العلاقات الإيرانية - السعودية 1941 -1979

(دراسة تأريفية سياسية)

د. ا مهمد عبد الرحمن يونس عيدان

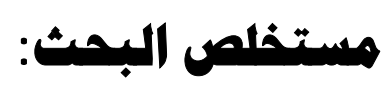

يسلا هذا البهث الموسوه "الللفلت الإيرلني ة - اللس عودية 1941 -

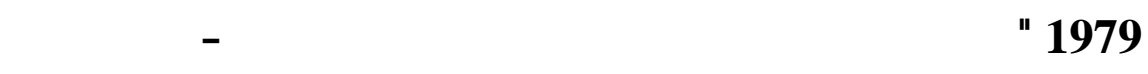

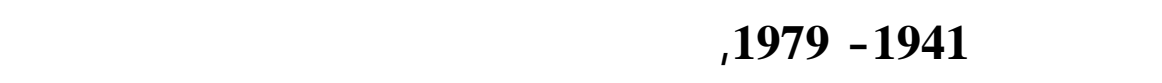
النكست آثارها عل الملافلت بين البلين.

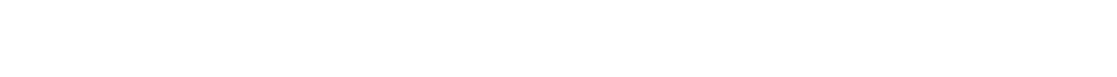

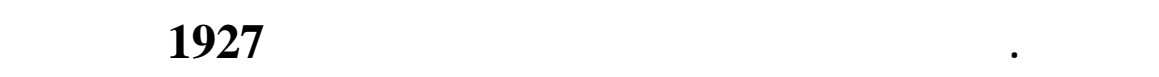

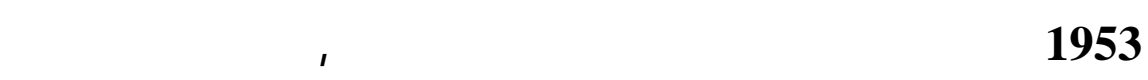

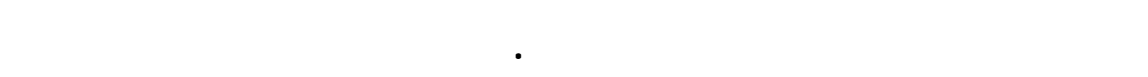

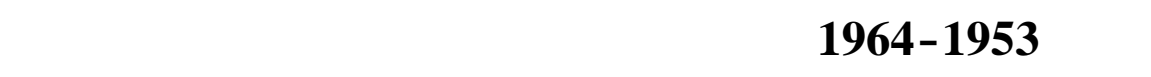

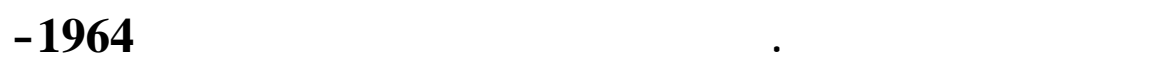

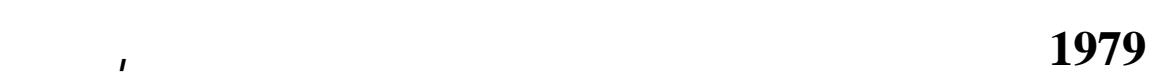
اللعاهن الكبير بينهمافي المجلات الأمنية ولافتصالية واللسيلسية والني النياني المكس بلوره علسيلسة البلين الخارجية في المهالقة. 


\section{العلاقات الإيرانية- السعودية 1941 -1979 دراسة تأربيفية سياسية}

\section{د. هممد عبد الرحمن يونس العبيدي*}

المقدهمة :

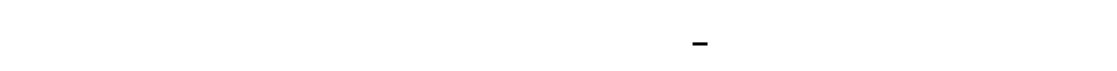

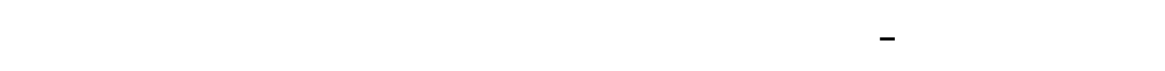

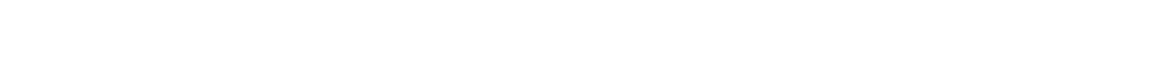

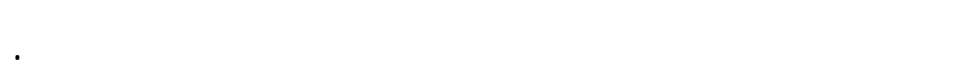

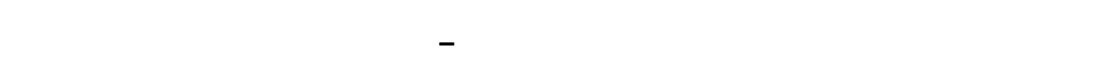

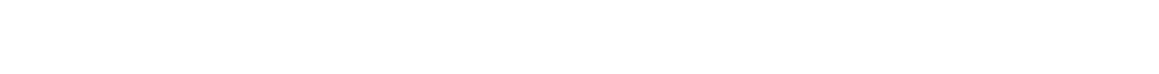

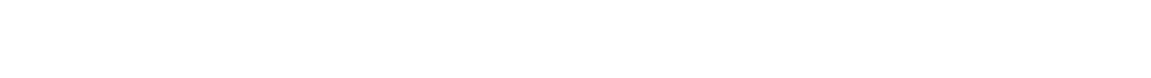

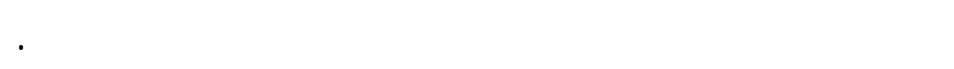

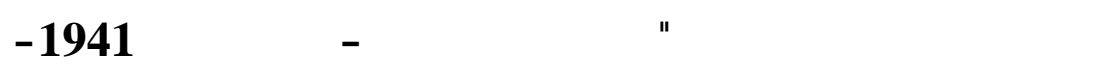

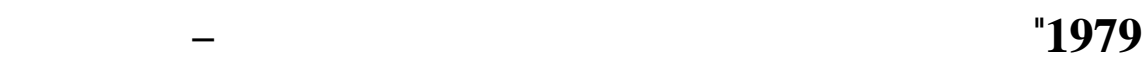

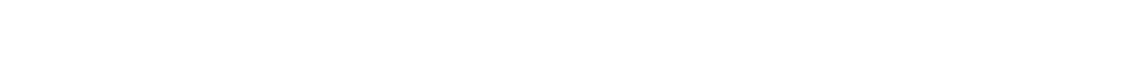
والدولية التي تركت الثارها بشكل مبلثر عليها. 


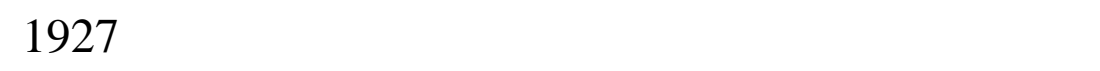

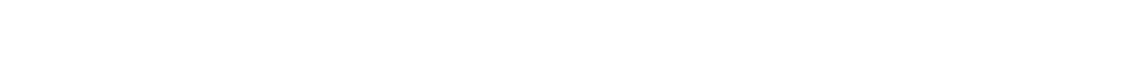

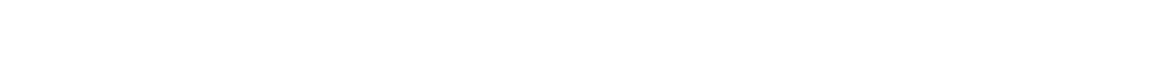

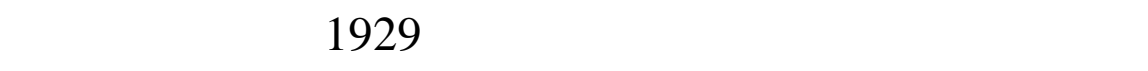

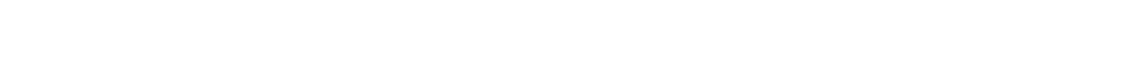

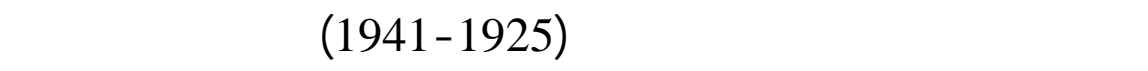

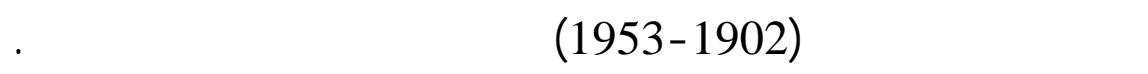

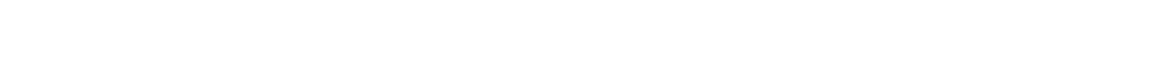

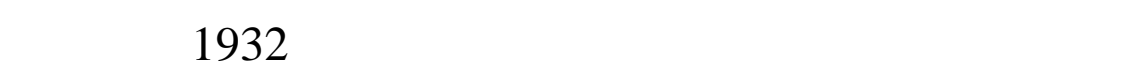

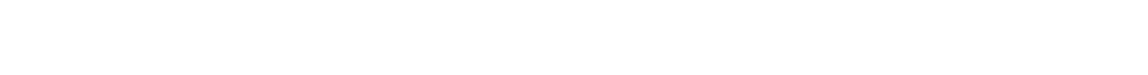

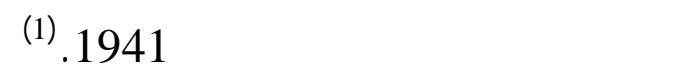

\section{الهلفلت بين عاي 1941 -1953:}

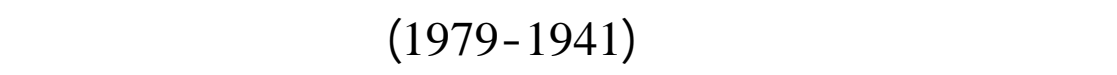

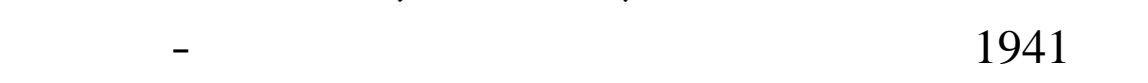

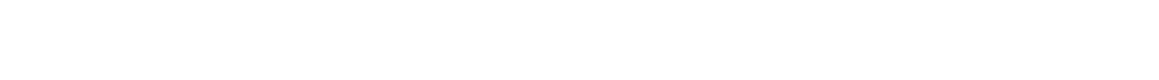

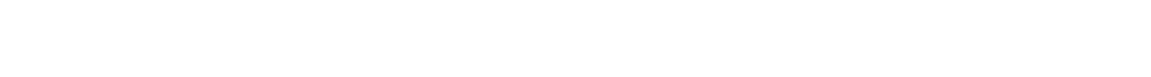

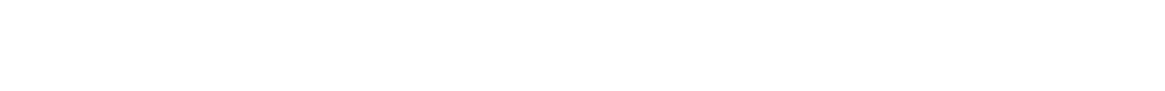

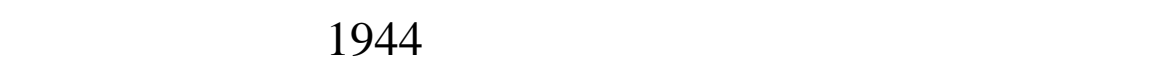

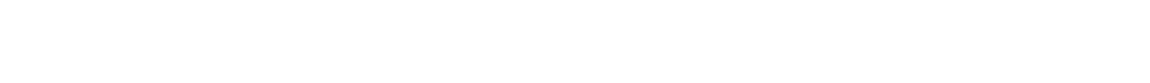

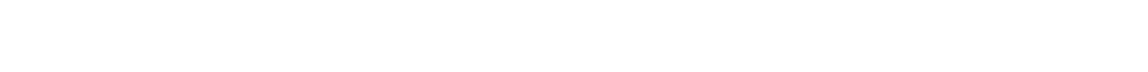

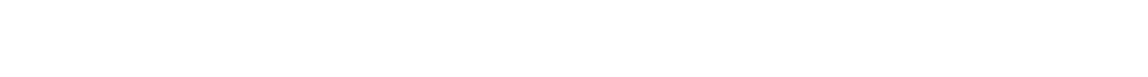




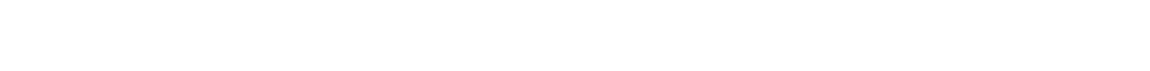

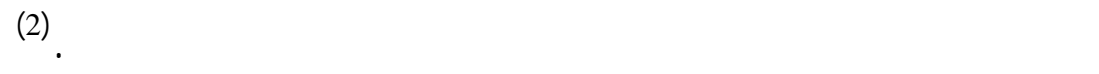

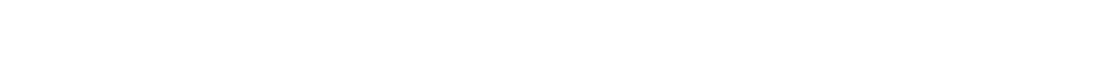

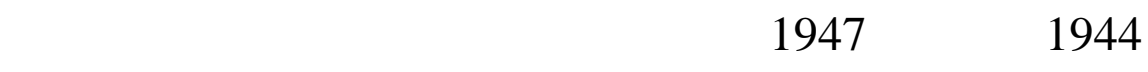

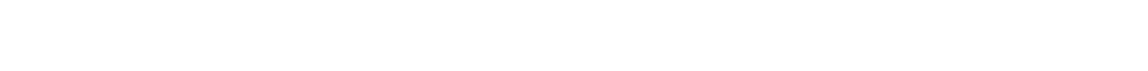

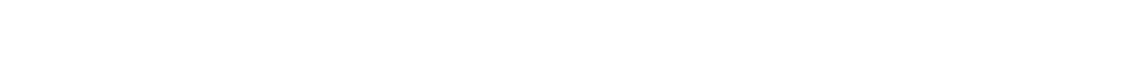

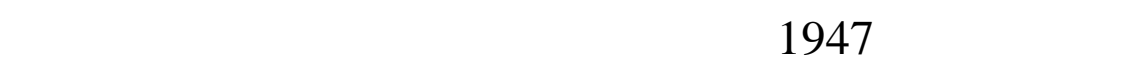

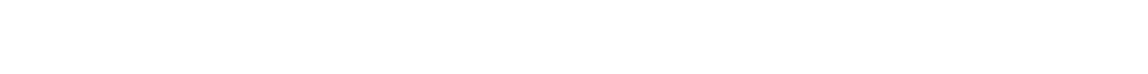
النطية، وهو الامر الذيشجع كثيرأ لمن زيارة القارب بين البلينين.

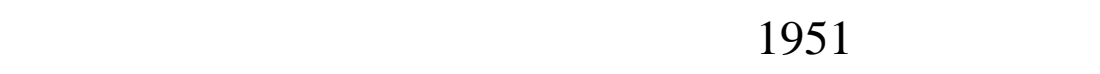

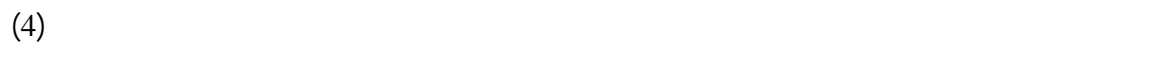

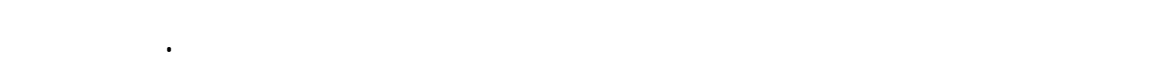

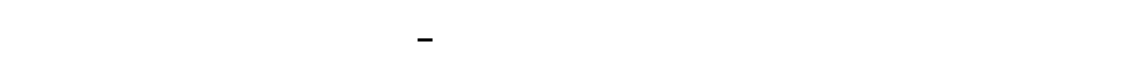

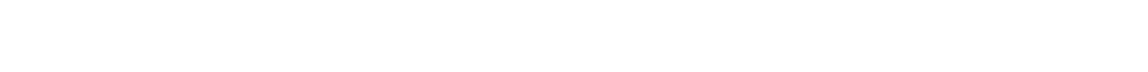
تجاهها، حق عولة اللها اله إيران علم 1953.

\section{الملفلت بين علي 1953 -1964:}

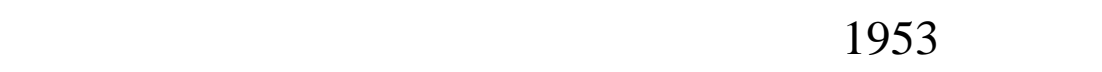

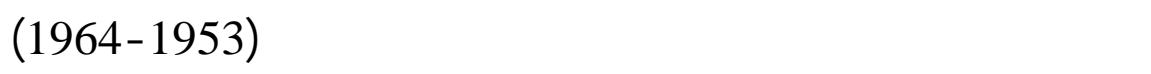

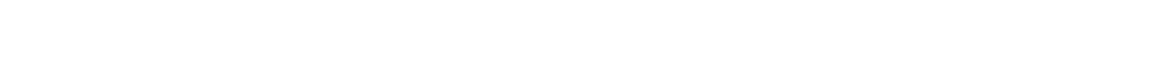

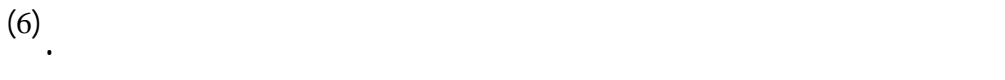




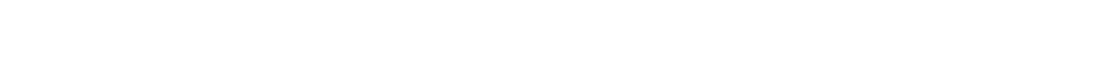

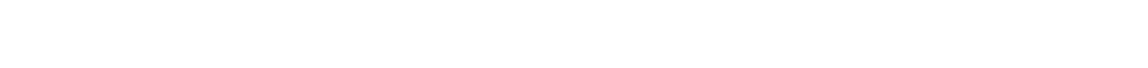

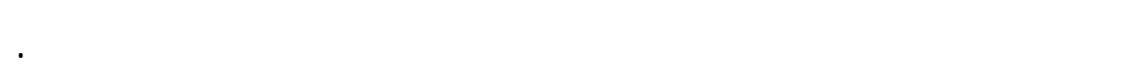

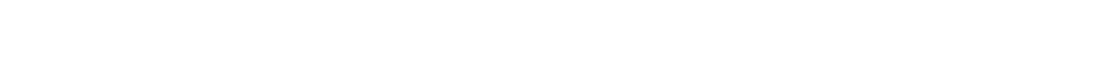
الثررق الاوسط، والتي تركت الثارها المبلثرة على دول المطقة وعلاقاتها

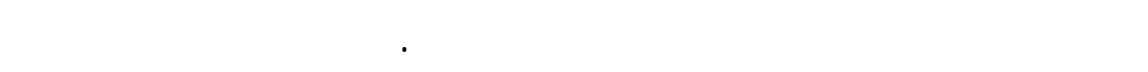

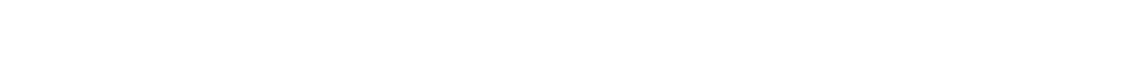

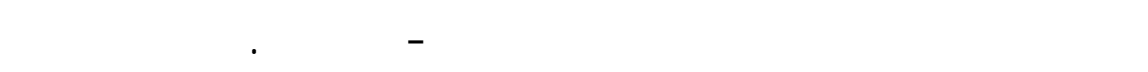

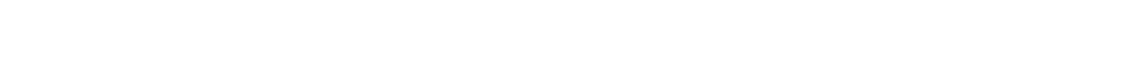

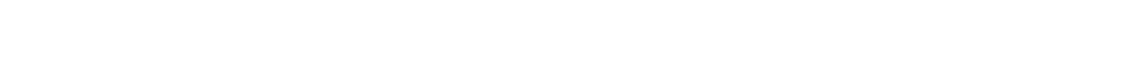

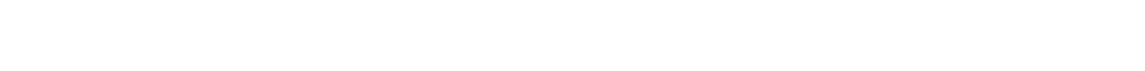

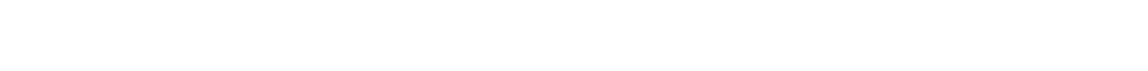

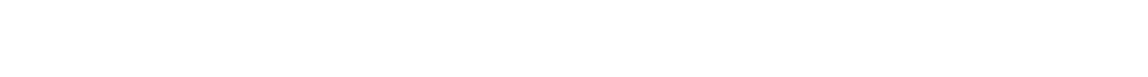

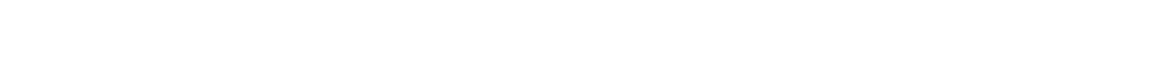

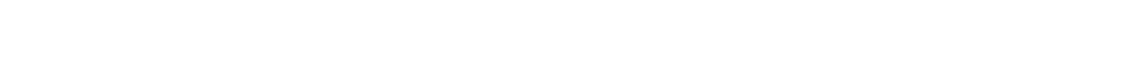
ومسانتنها . (7)

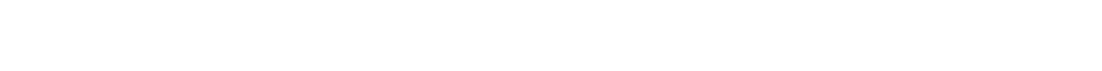

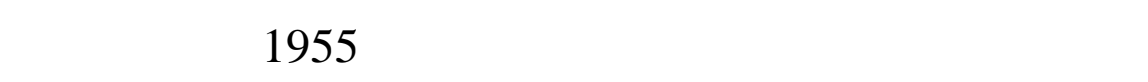

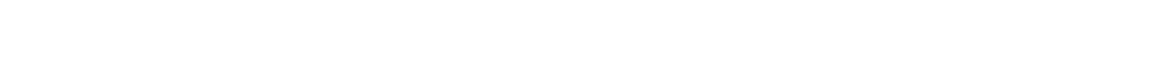

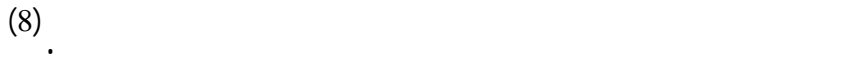

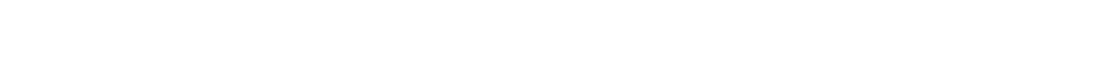

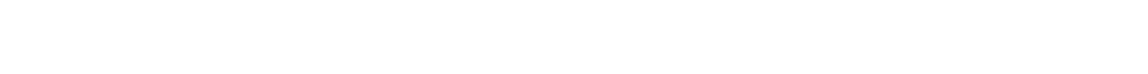

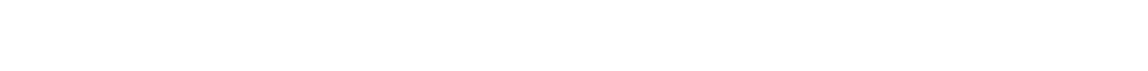




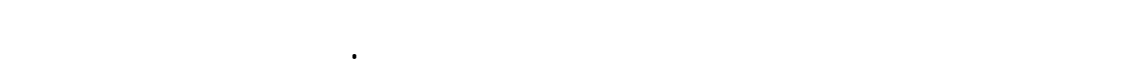

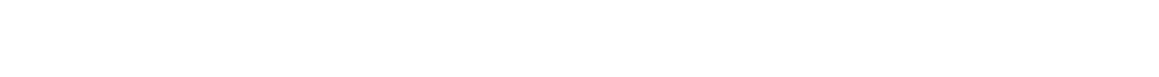

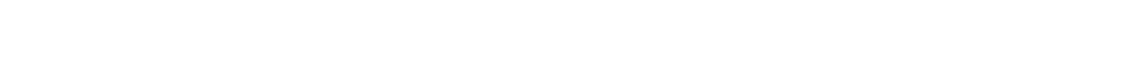

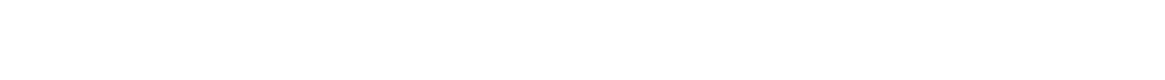

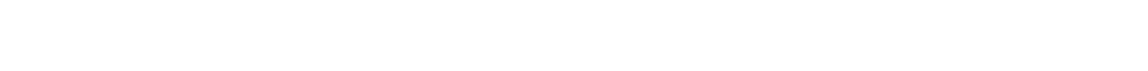

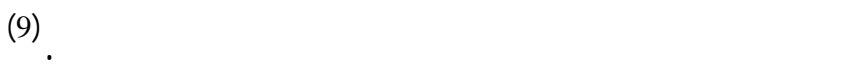

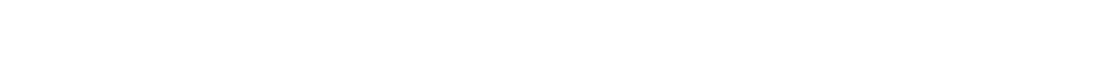

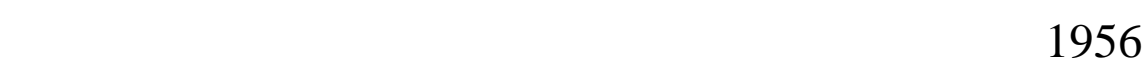

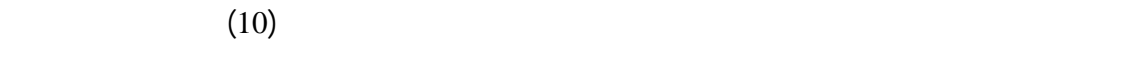

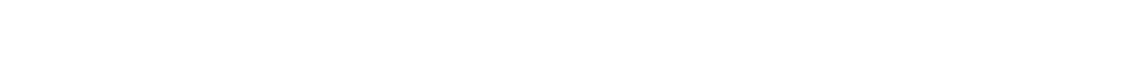

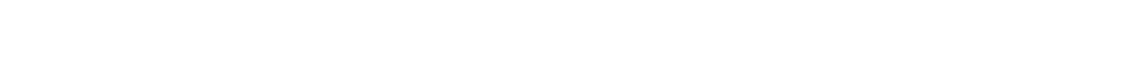

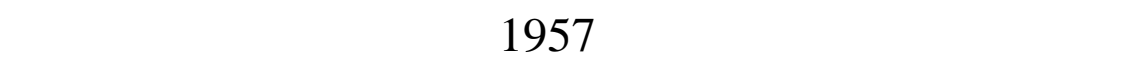

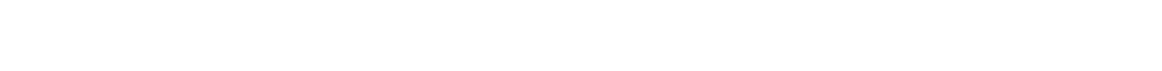

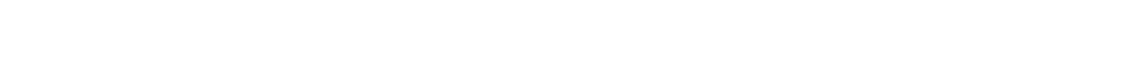

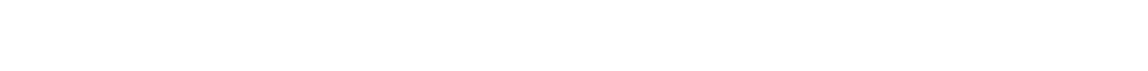

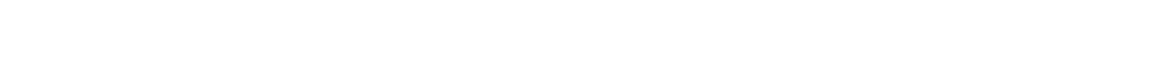

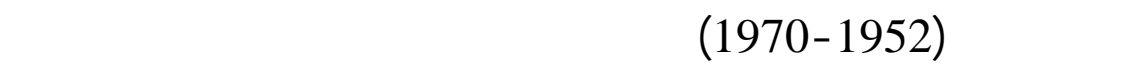

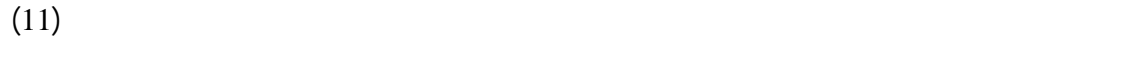

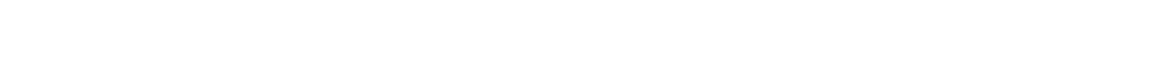
وللسلام في مطقة للثررق الاوسط والموقف من القضية الفلنطينية (12).

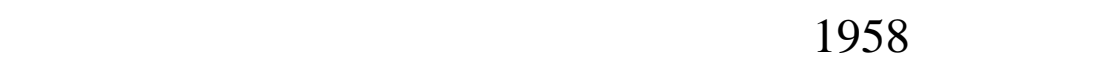

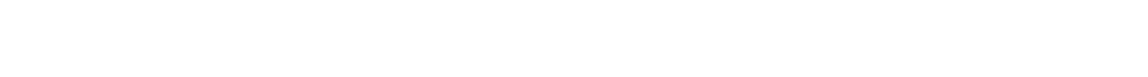

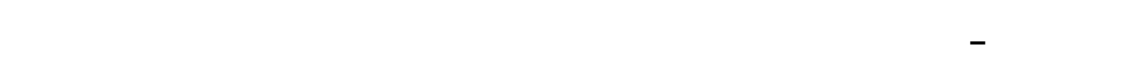


نتيجة لميلسة عبد الناصر القومية والتحررية، والتي كانت كل من لي -ران

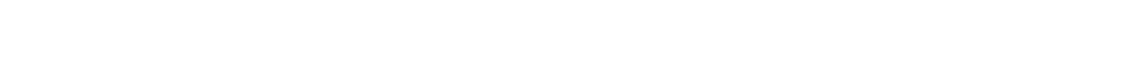

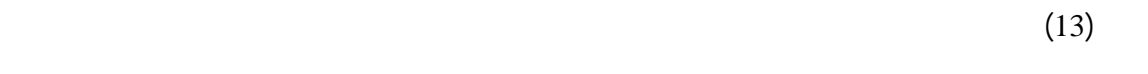

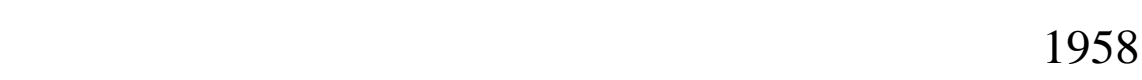

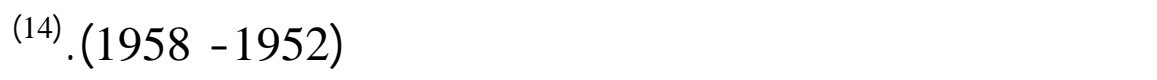

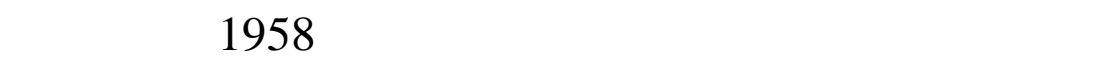

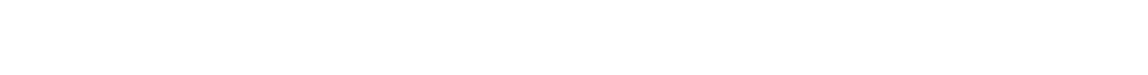

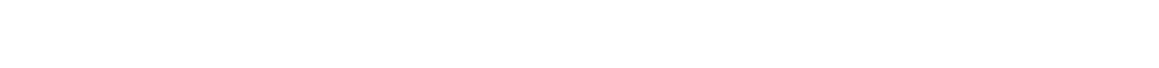

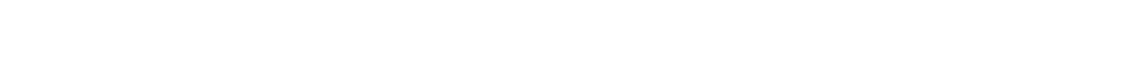

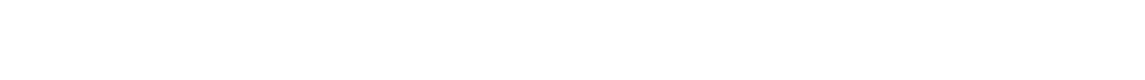

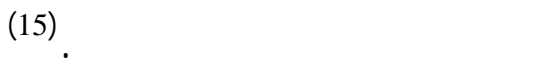

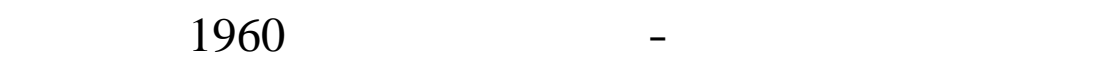

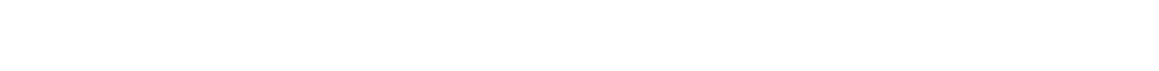

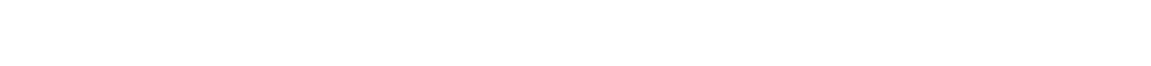

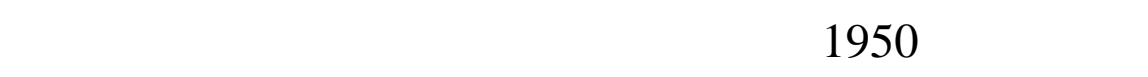

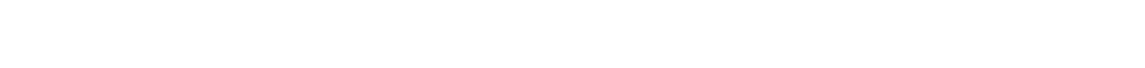

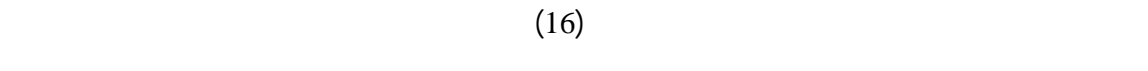

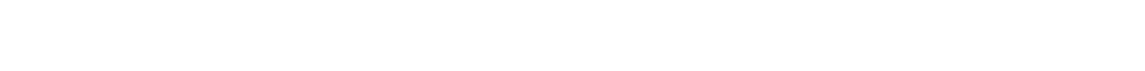

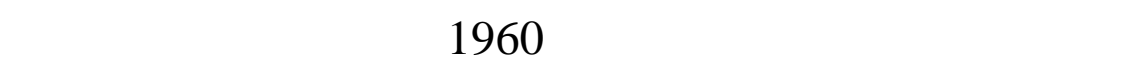

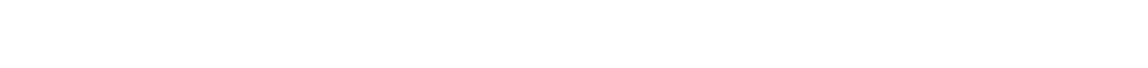

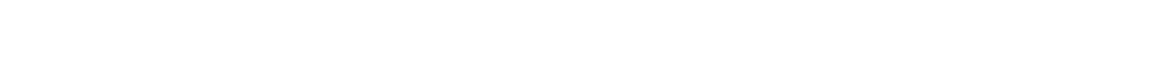

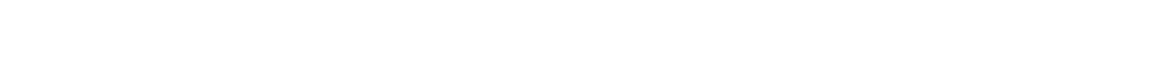


2007)

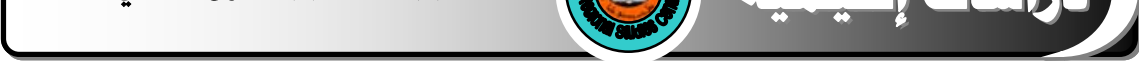

دفعها نحو التهيد بتوسبع المقلطعة . (17)

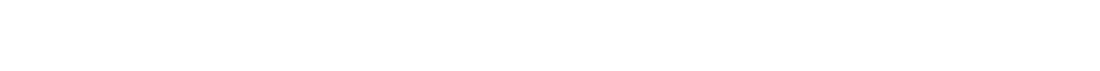

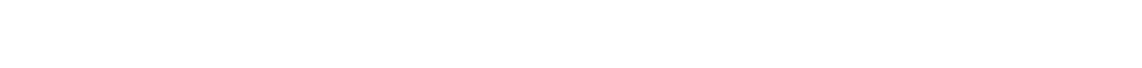

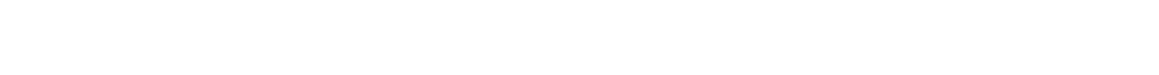

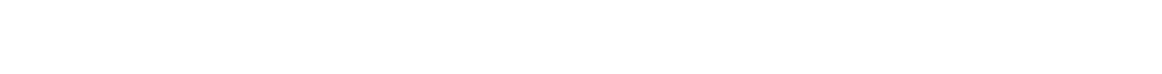

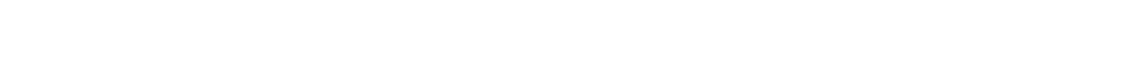
كثيرا عما كانت عليه قبل الاعلان. (18) سارت العلاقلت بن الجانبين بعد ذلك، وفق مبدأ التعاون والمص الح

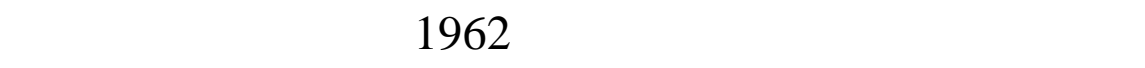
لسقط الظلم الملكي، ونشوب الحرب الاهلية اليمنية بـ ـين الجمه -وريين

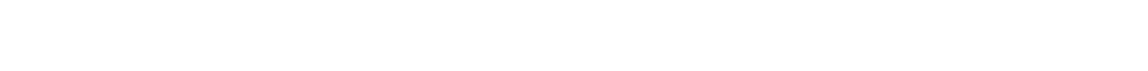

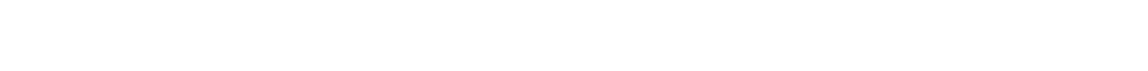
وقيل الرئيس جمل عبدالناصر بنقديم الدعم العسكري للظّلم الجيد ف ي

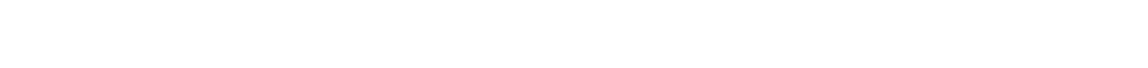

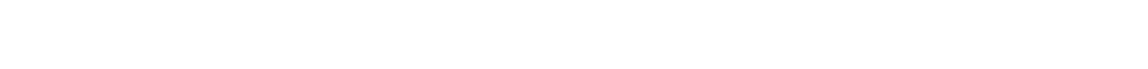

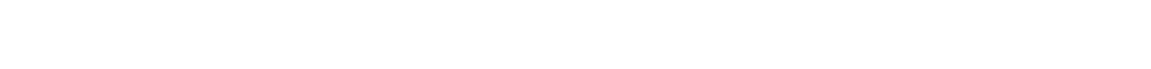

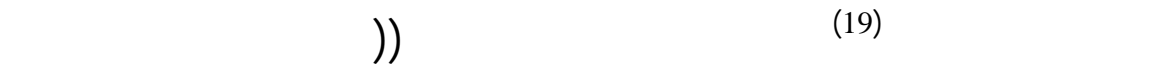

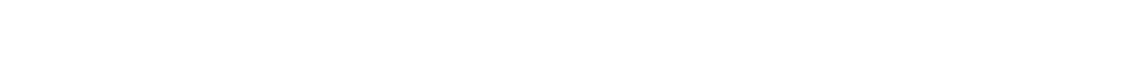

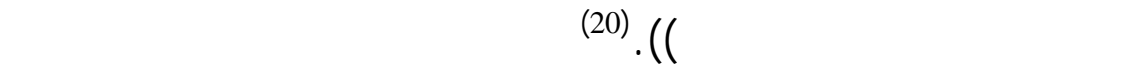
للمملكة العربية للسعونية في جهودها ودعمها للملكين في اليمن، وقلمت

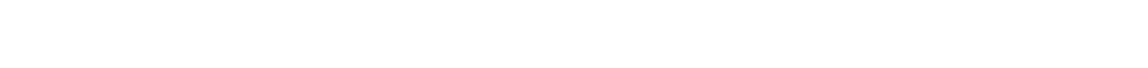

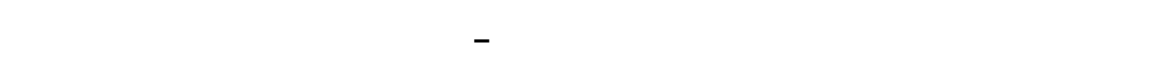
البلدين الاقليمية . 


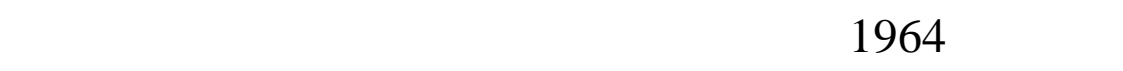

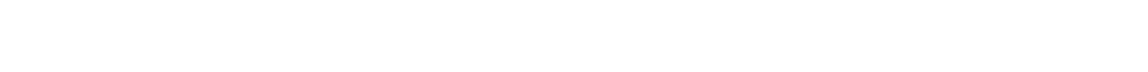

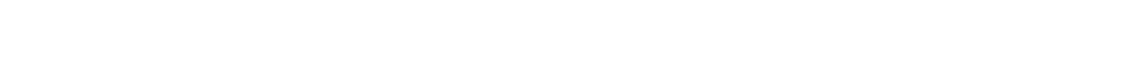

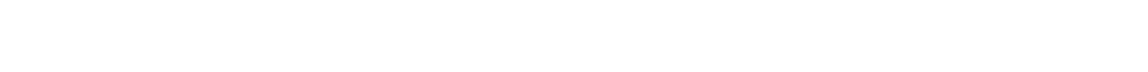

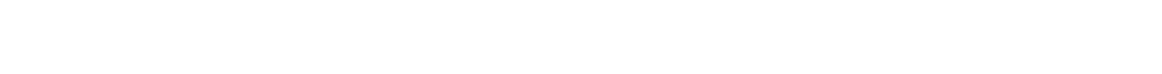

سعود .

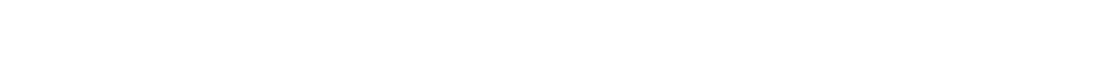

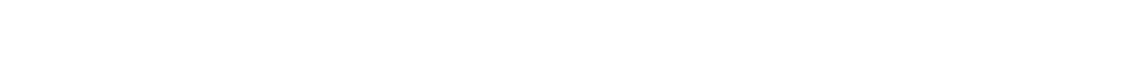

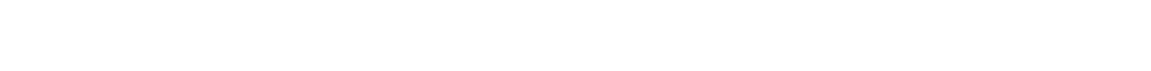

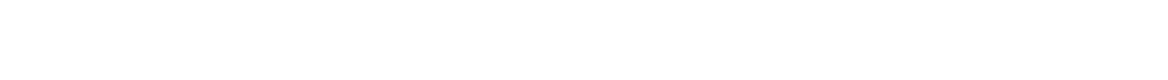

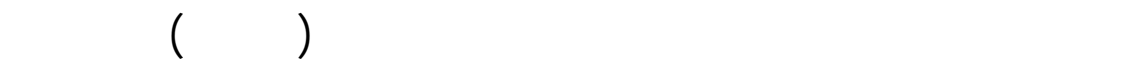

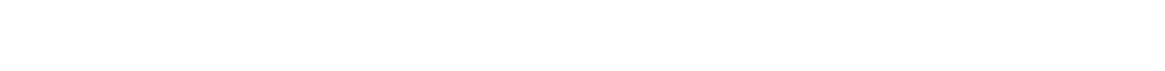

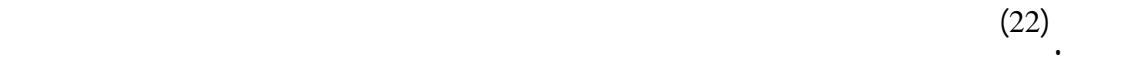

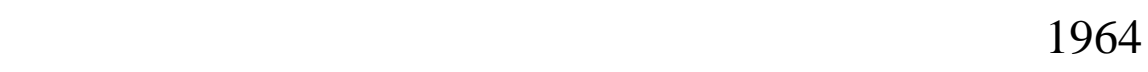

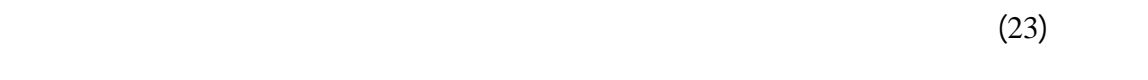

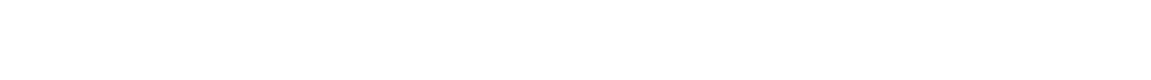

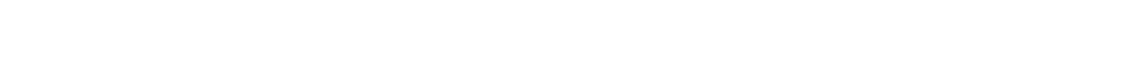
وطهران. (24)

وفي علم 1965 وضمن لطار الدعوة اله التضلمن الإس الماهي زار

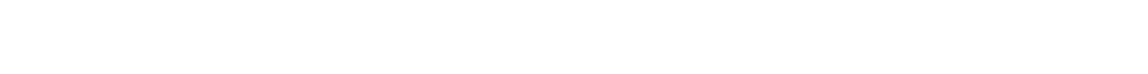

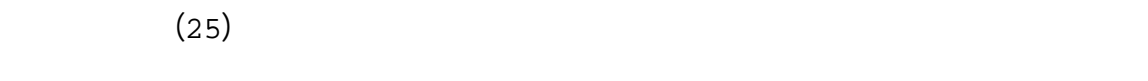

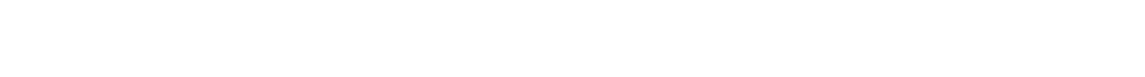




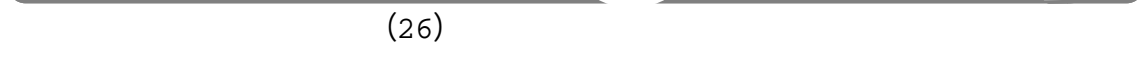

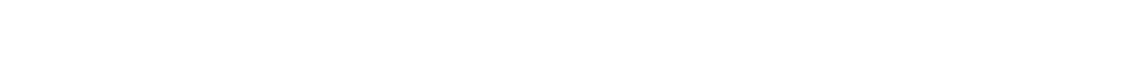

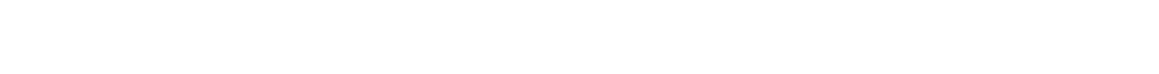

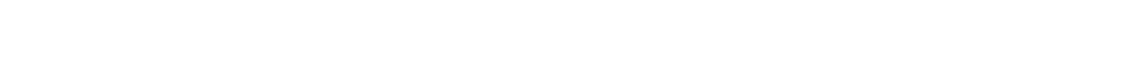
فضلاً عن بهث مسألة تحنيد الجرف القرير القاري بين البلدين. (27)

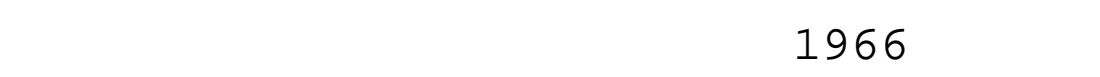

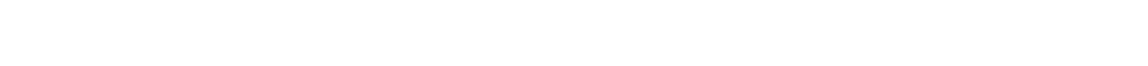

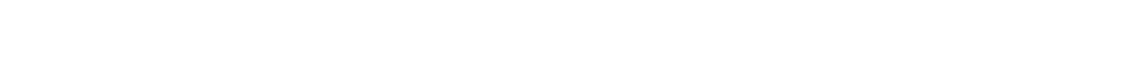

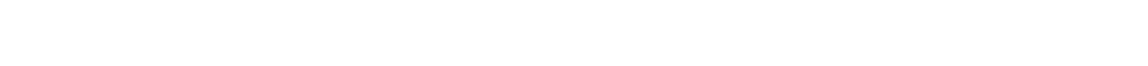

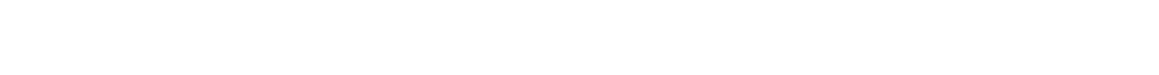

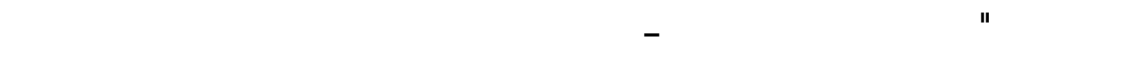

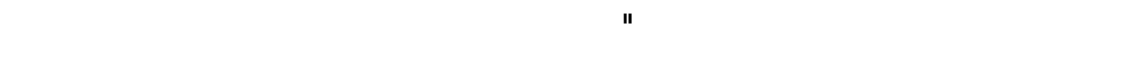

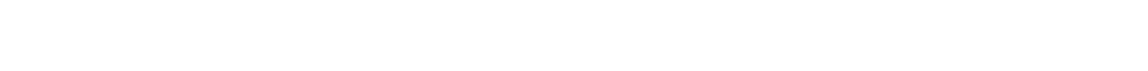
البلنين. (28)

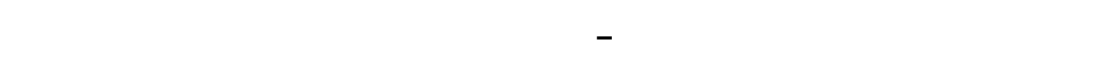
ايران من حرب حزيران علم 1967، حيث نددت ايران علناً بالاحتلال

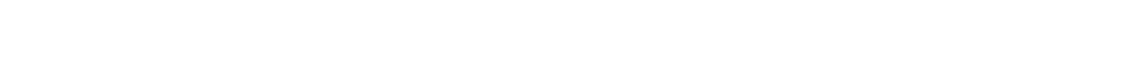

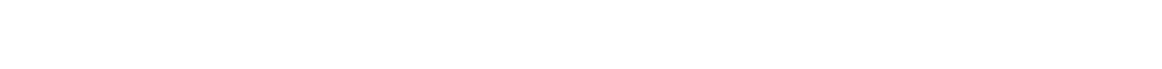

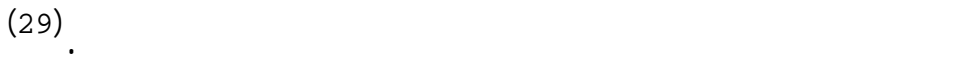

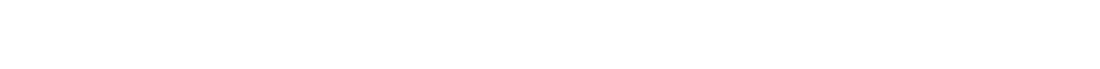

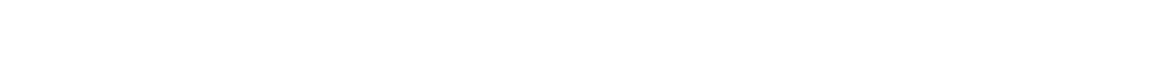

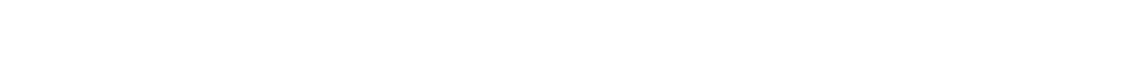

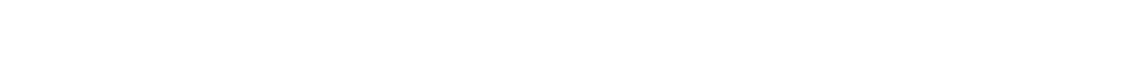


اهمية تبالل ولستمرار الزيارات الرسمية بين البلين، ودعى الملك فيصل في نهاية زيارتهشاه ايران لزيارة اللسعوية. (30)

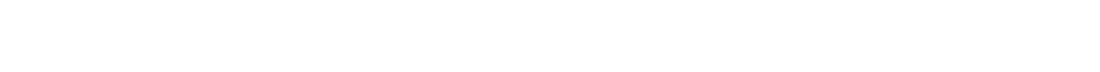
ذلك لم يمنع من تعرضها لبعض وصن التحديت ولمسيما منذ علم 1968 الث -ر

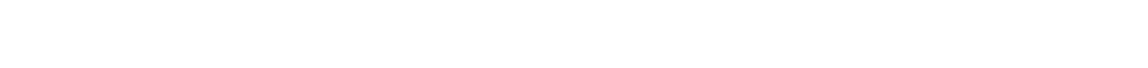

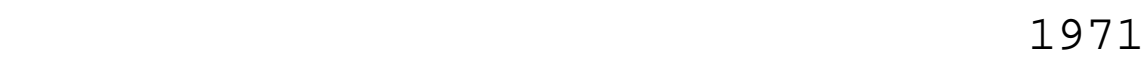

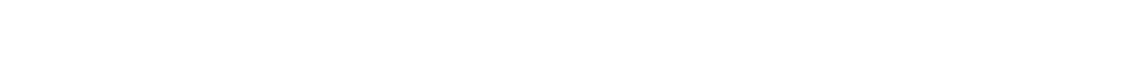

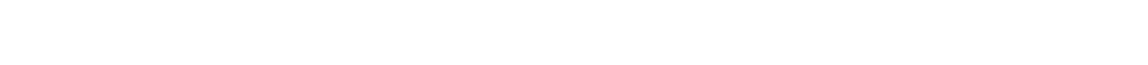

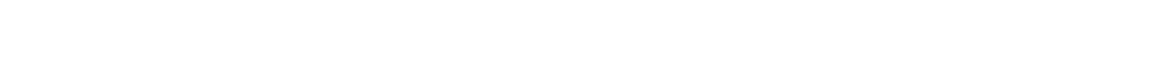

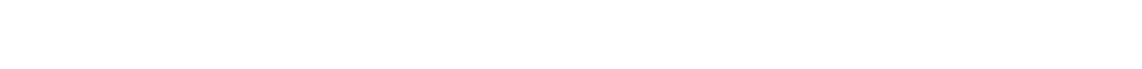

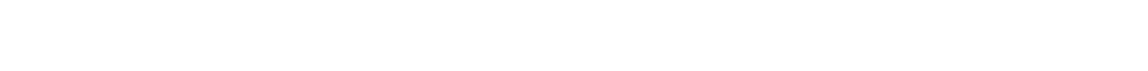

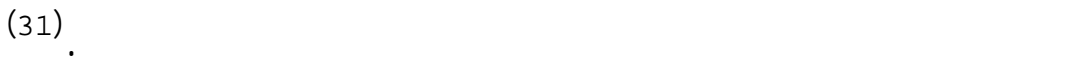

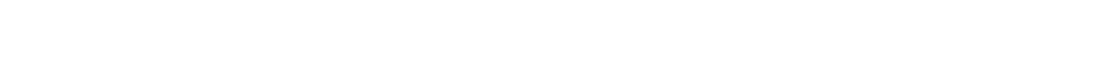

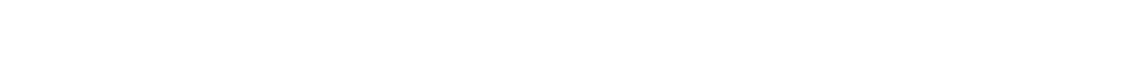

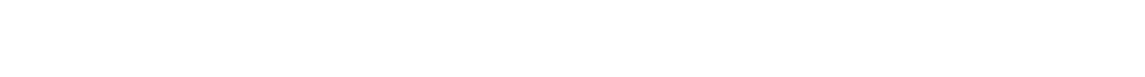

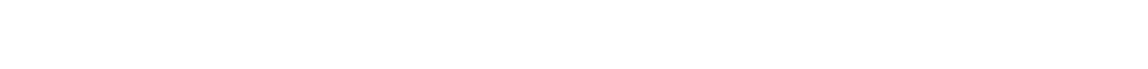

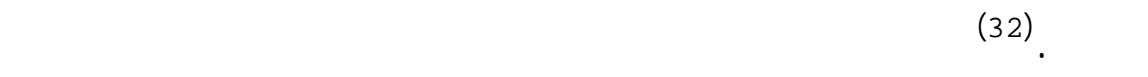

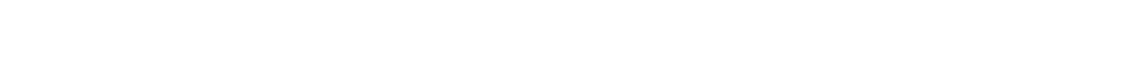

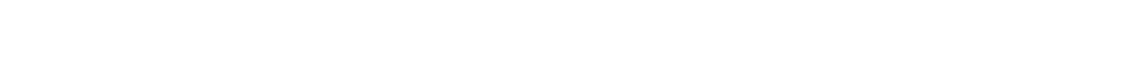

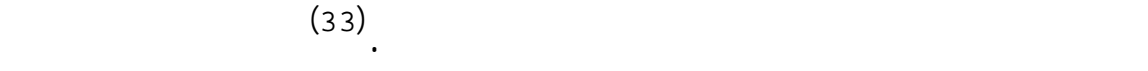

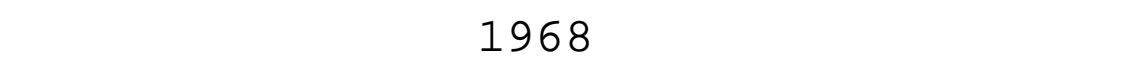

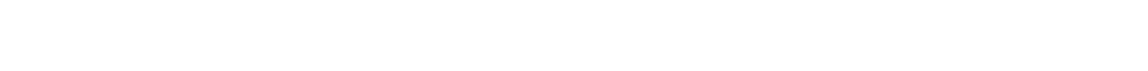

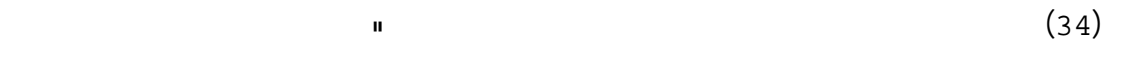




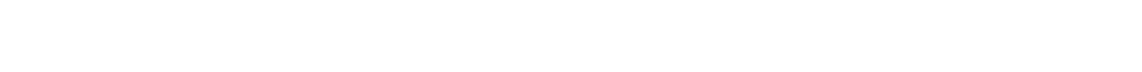

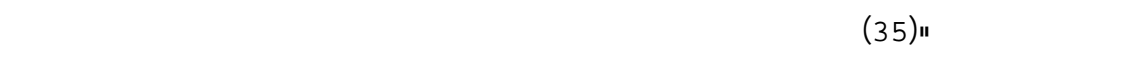

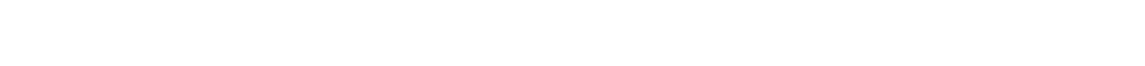

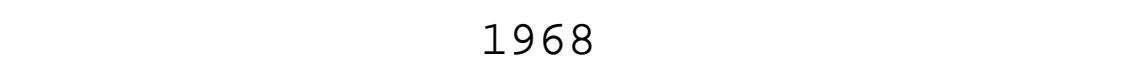

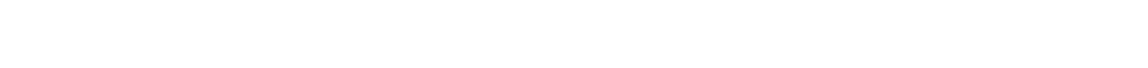

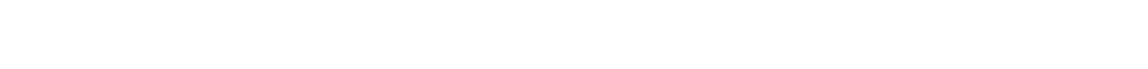

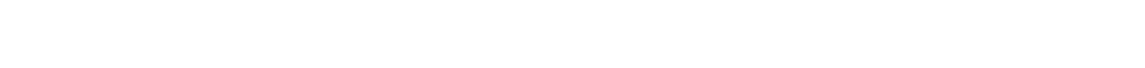
ذاته (36)

وتلبية لدعوة الملك فيصل قلم اللثه بزيارة للسعودية في تثرين الثاني

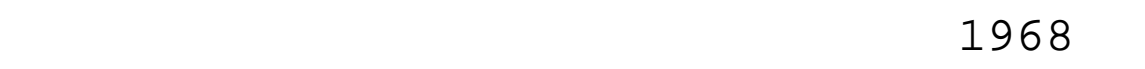

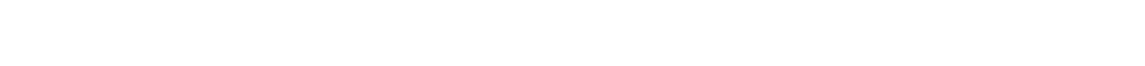

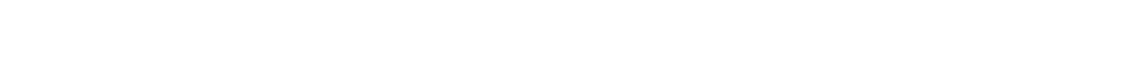

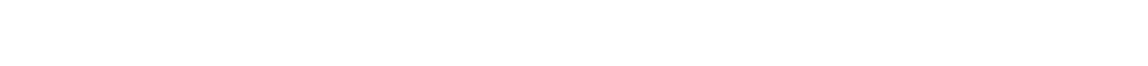

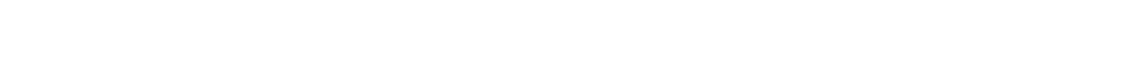

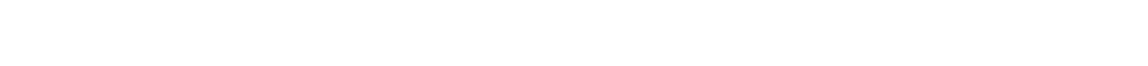

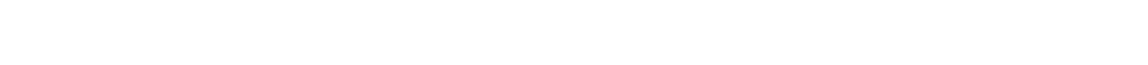

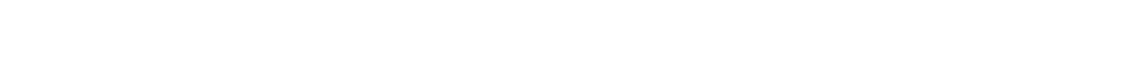

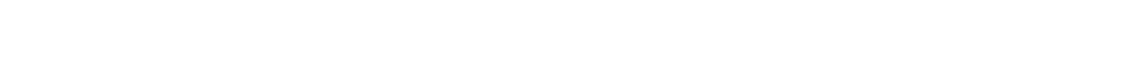

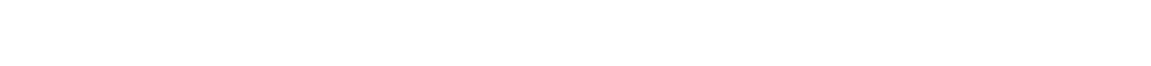

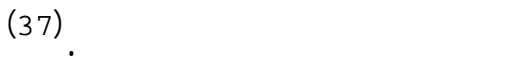

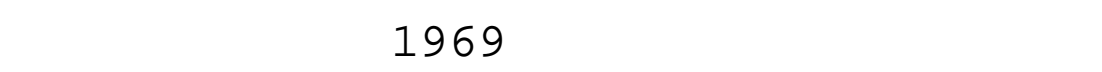

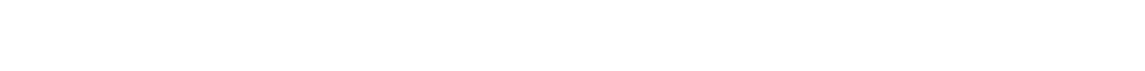

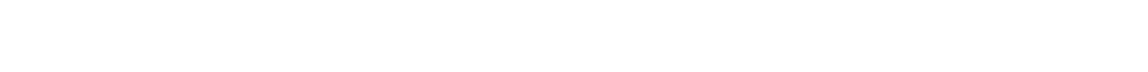


قرير مصيره(38) فضلاً عن القاء الذي جمع الملك فيصل وشله الي -ران، المان.

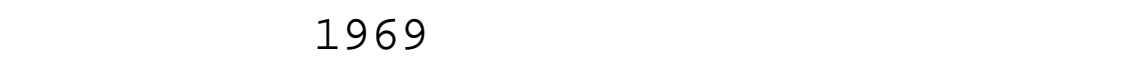

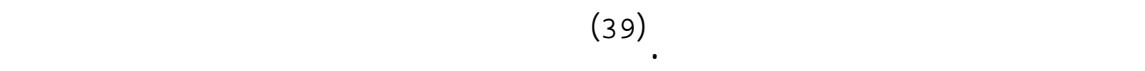

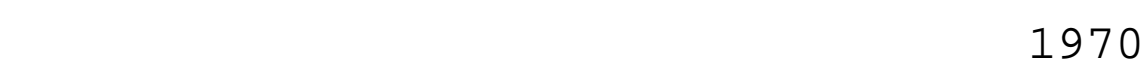
العلاقلت للسعودية - الايرانية. القد دفع الانسحلب البريطاني، وقيل اللنطول الإنية اللسوفيتي بتكرار جولاته

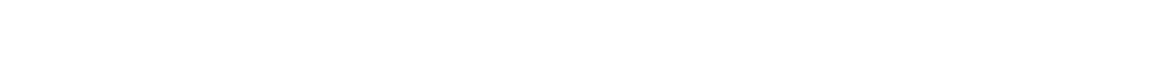

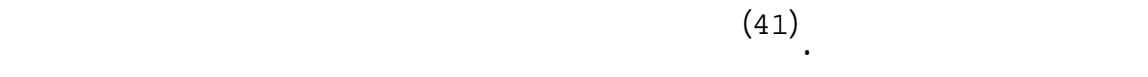

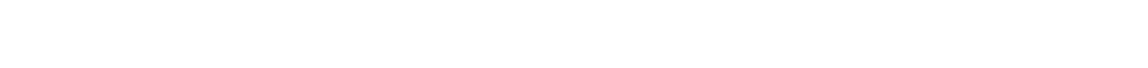

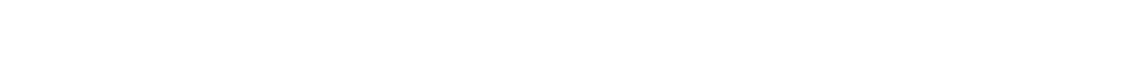

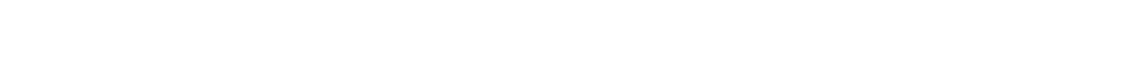

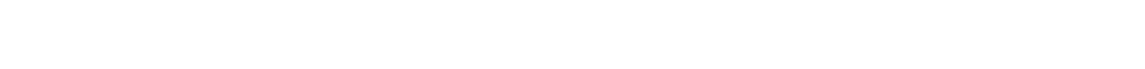

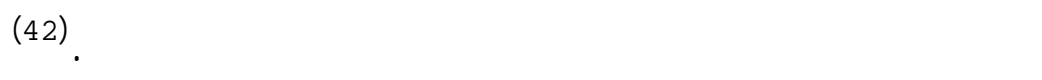

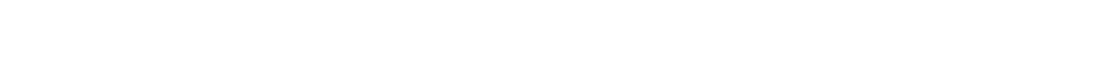

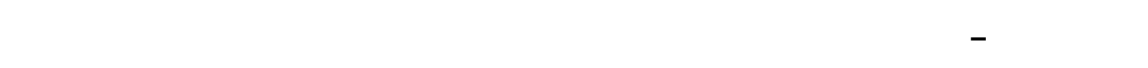

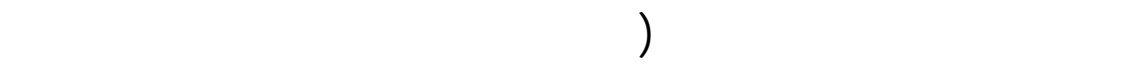

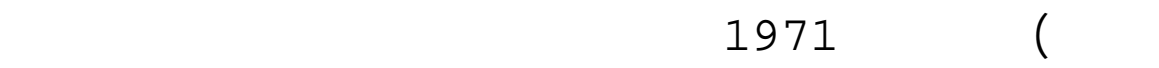

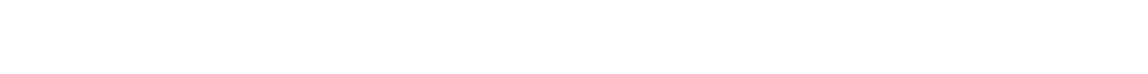

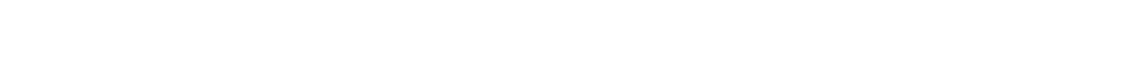

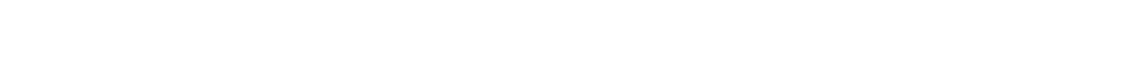

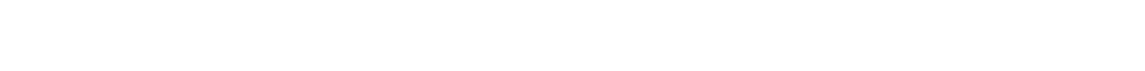




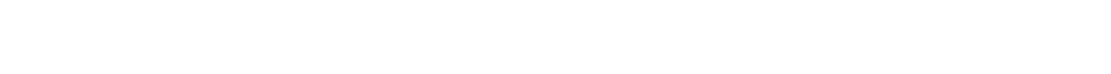

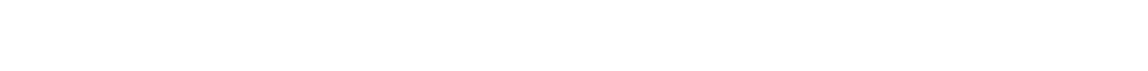

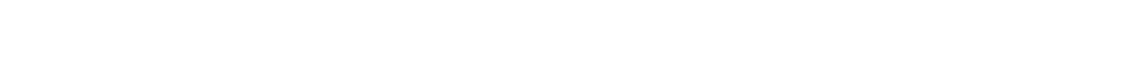

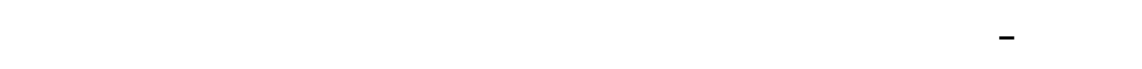

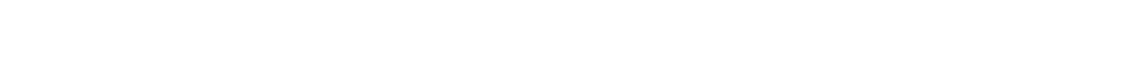

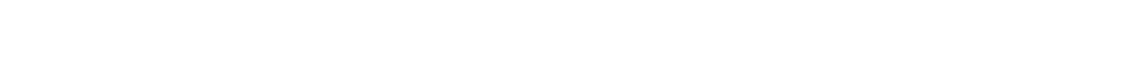

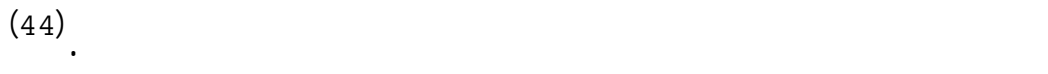

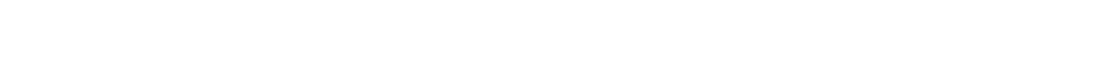

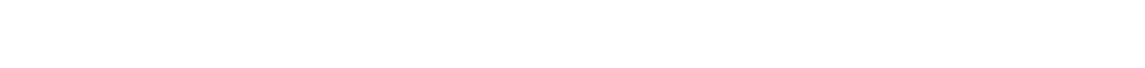

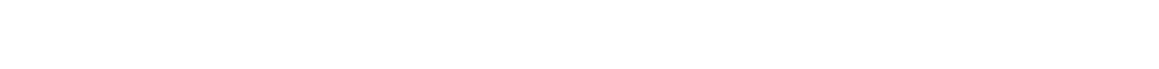

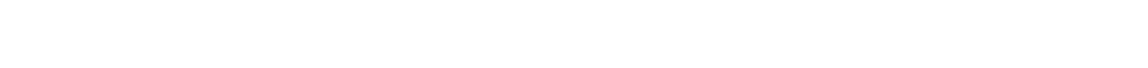

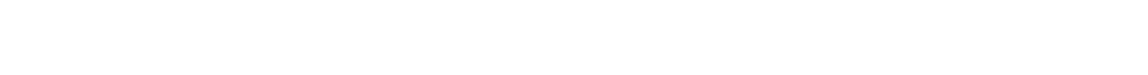

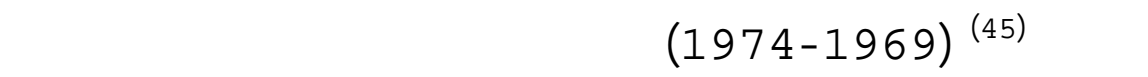

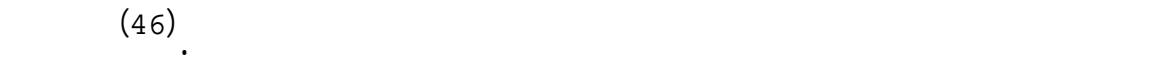

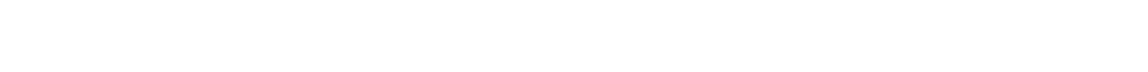

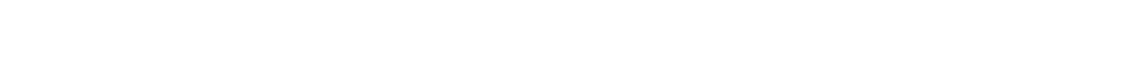
الايرانية aن الاقليم. (47)

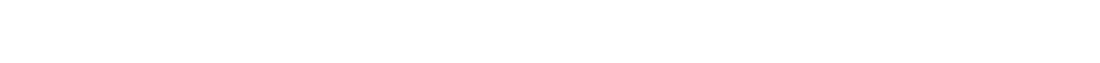

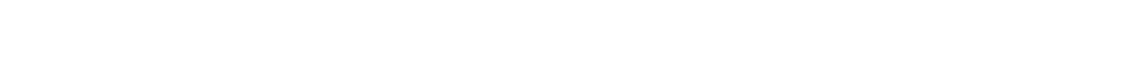

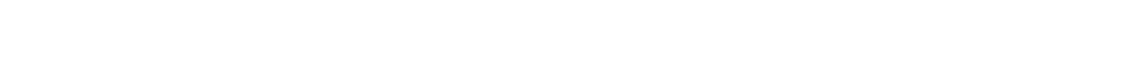

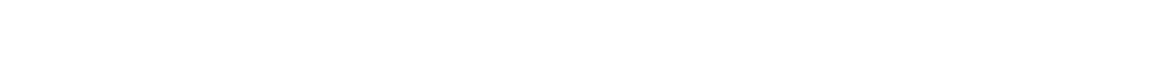

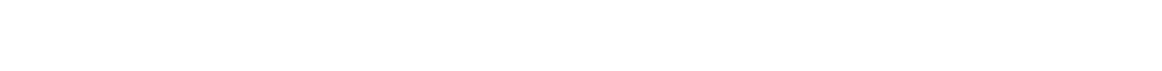


وقيت موضع خلاف بين البلنين وبلدان الخلبج الخرى حتسقوط للشه عل 1979 (48)

وفيشهر نيسلن من علم 1975 نخلت العلافلت للسعودية - الايرانية

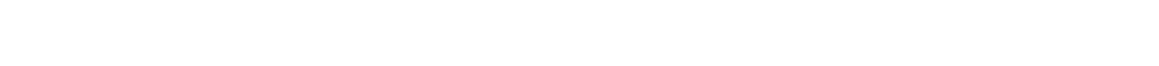

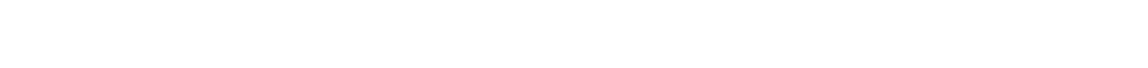

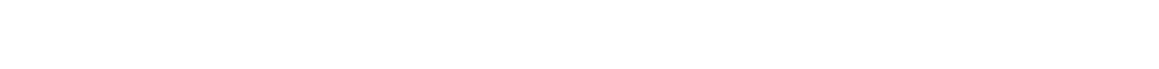

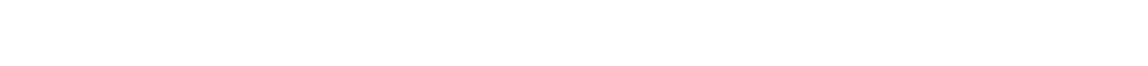

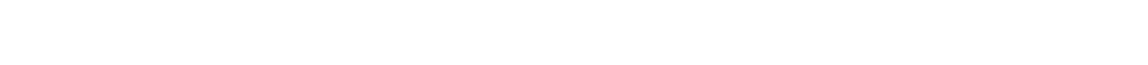

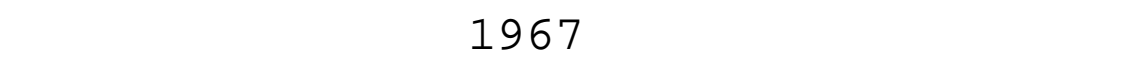

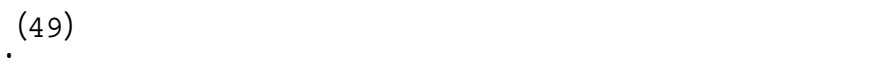

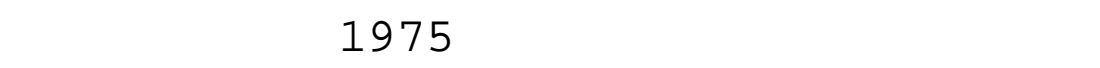

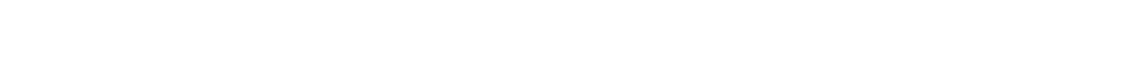

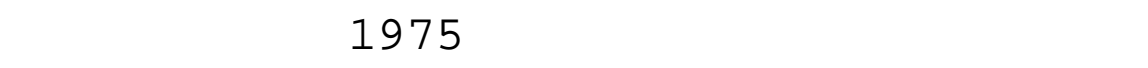

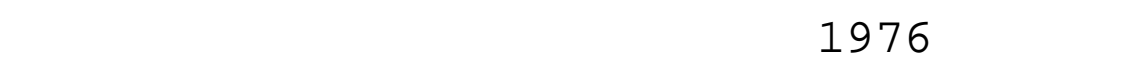

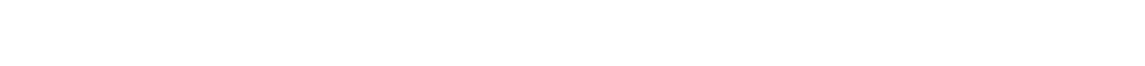

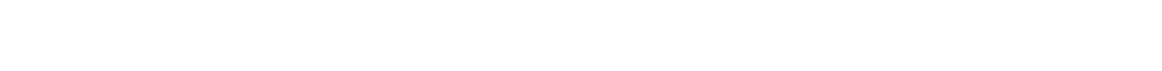

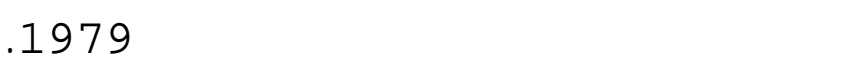

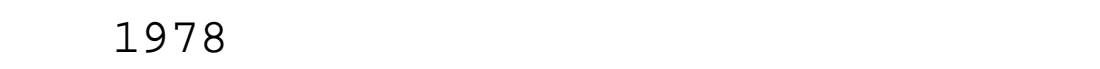

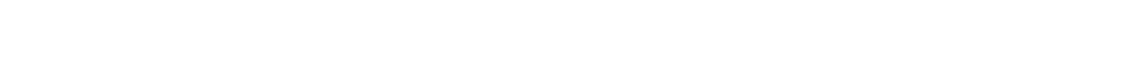

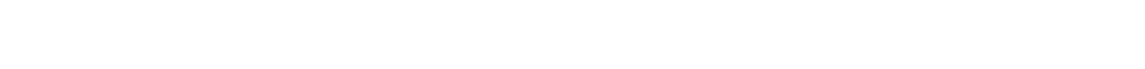

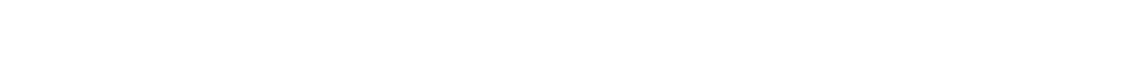

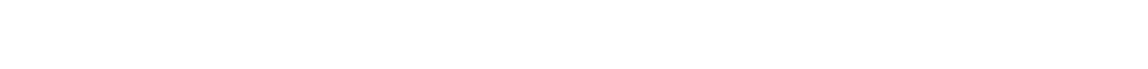

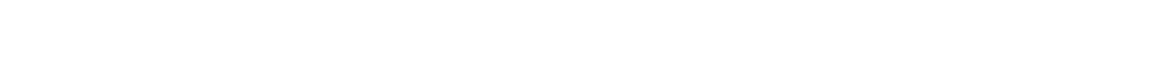




\section{خالتم}

لكتبت العلاقت للسعوية - الايرانية اهمية متميزة على المس ـوتيين

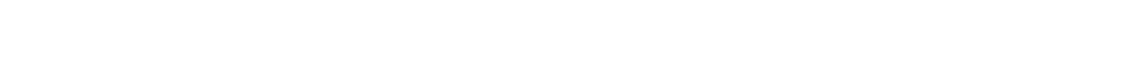

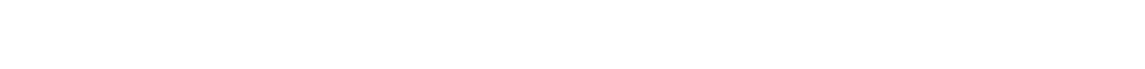

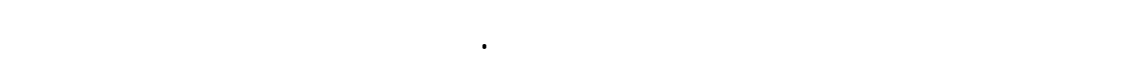

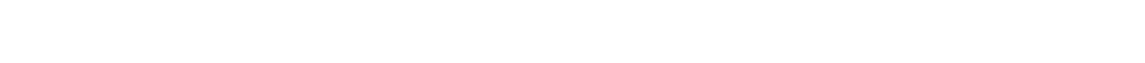

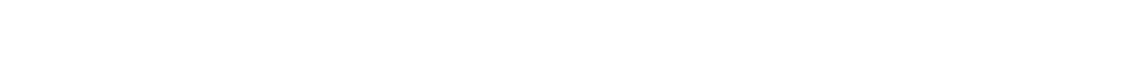

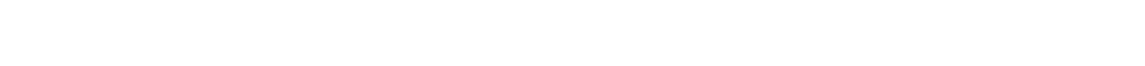

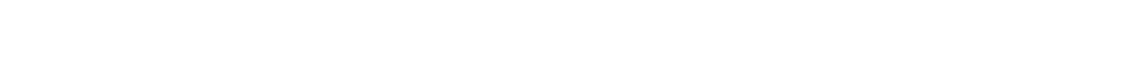

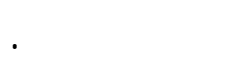

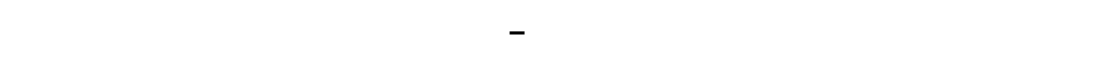

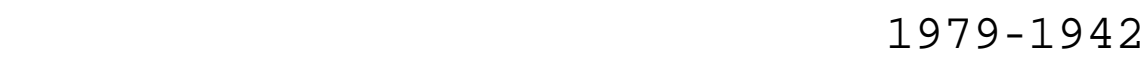

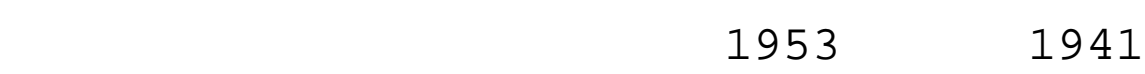

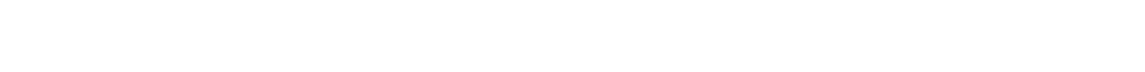

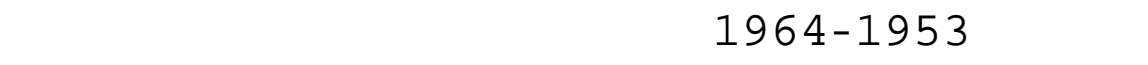

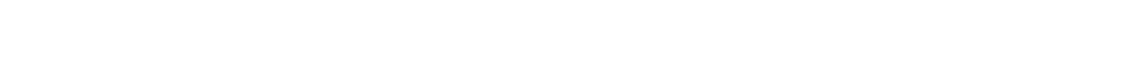

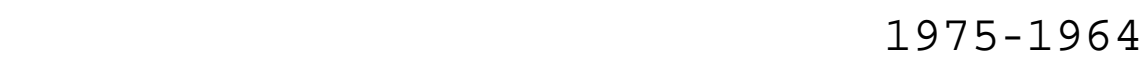

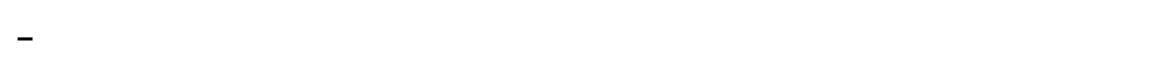

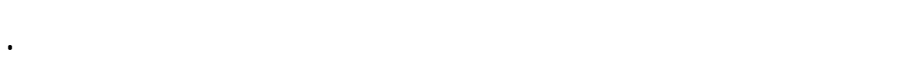

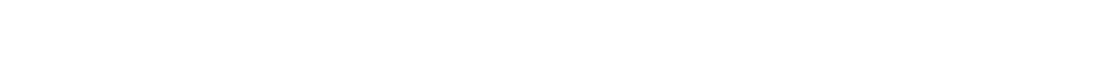

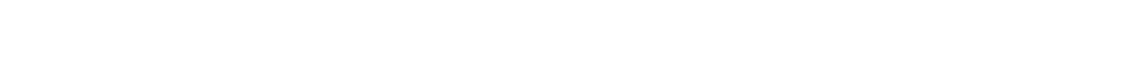

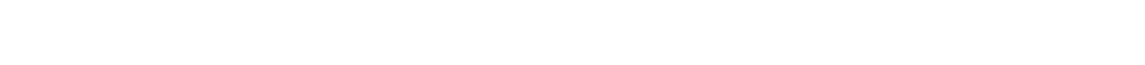

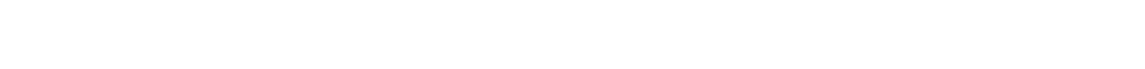

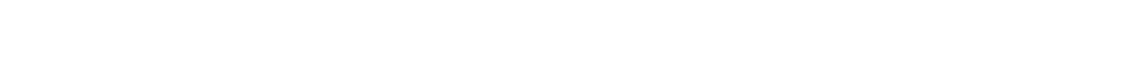

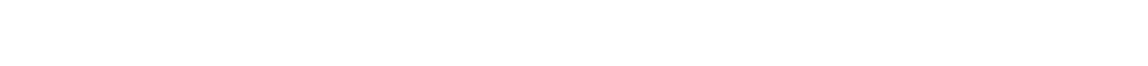

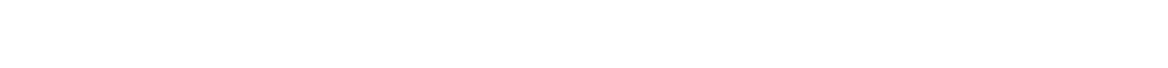
بينهما والمحلظة على متانتها قدر الامكلن. 


\section{الهولش والمصادر}

(1) سععيد بايب، الللفلت اللعودية - الايرلني ة 1932 - 1983، (دار الله الي

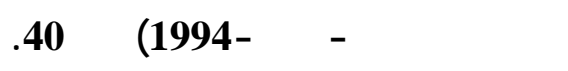

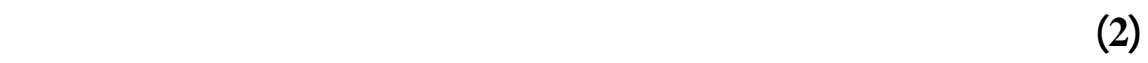

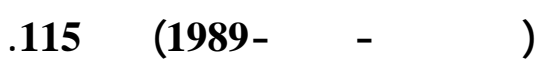

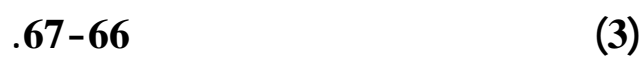

(4) الحدقاة الحركة الولنية في ليرلن، تزعم الجبهة الولنية الايرلنية وقاد حمالة

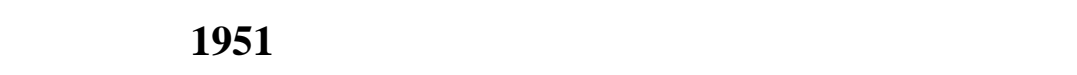

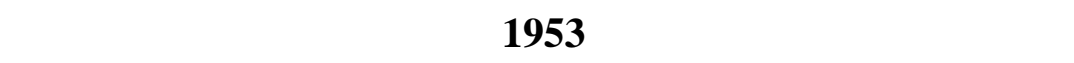

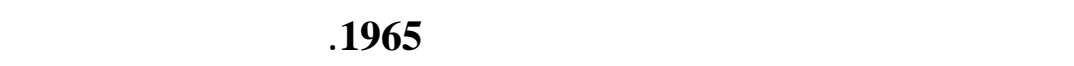

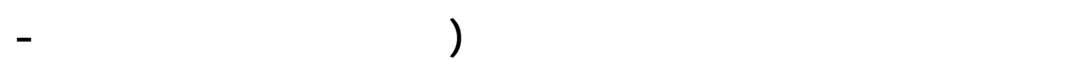

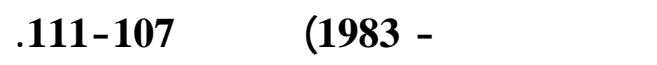

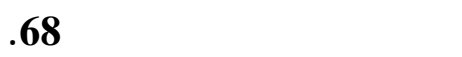

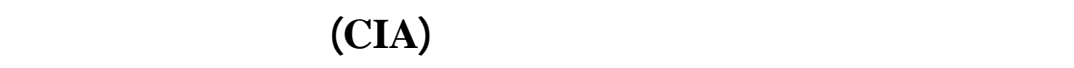

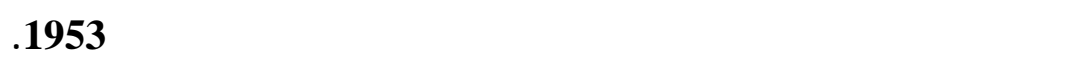

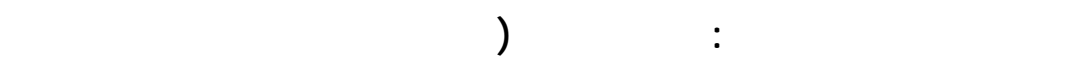

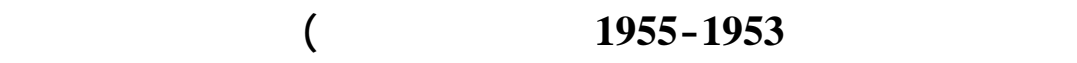

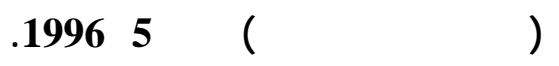

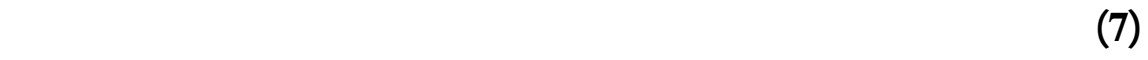
اللسرة البهلوبة 1925 -1979، (معهد البحوث والمرلسلت العربية - الفاهرة

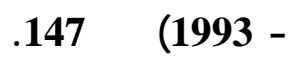


روح ال روضلفسيلسة اليرلن الخارجية 1941 -1973، ترجمة علي مجسن

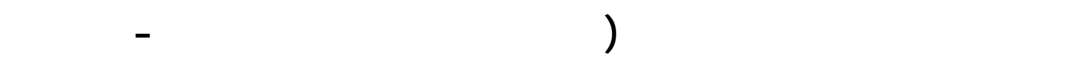

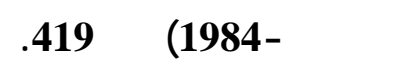

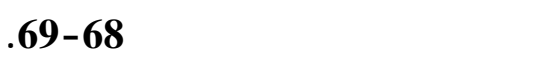

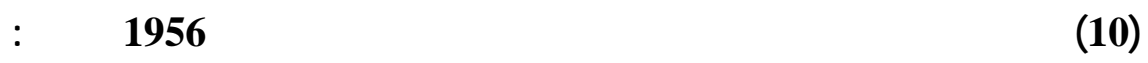

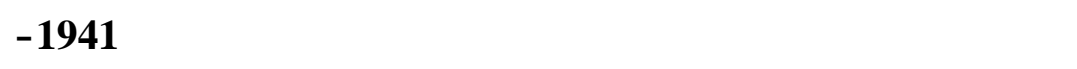

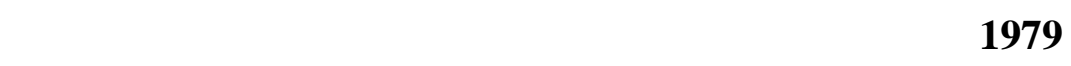

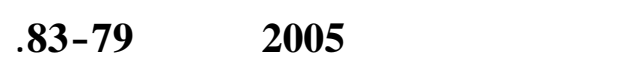

(11) فع والحة البريمي عند قملة الحود بين اللبعوية وعملن والمارة البوظلبمي،

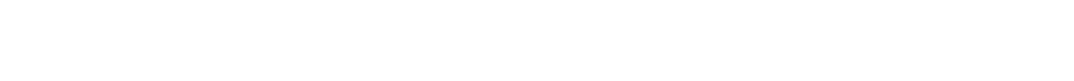

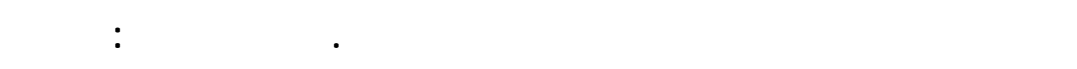

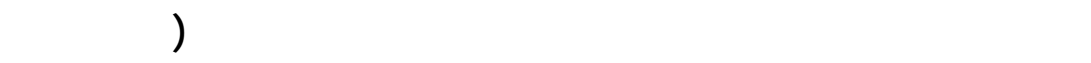

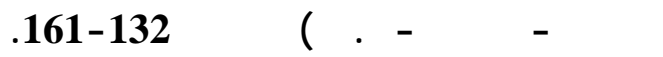

$$
\begin{aligned}
& \text { (13) باليب، المصر السلق، صبري، }
\end{aligned}
$$

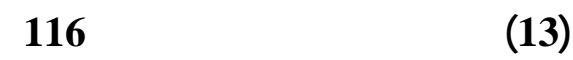

Mordekchai Abir, Oil Power and Politics, (London-1974), P.6. (14)سيلسي لبنالي ولد علم 1900 دوس القلنون ولافتصاد اللسيلس، تول رئلسة

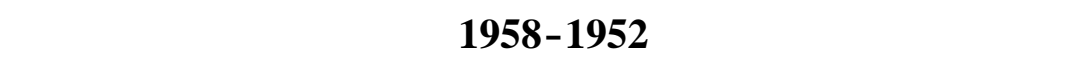

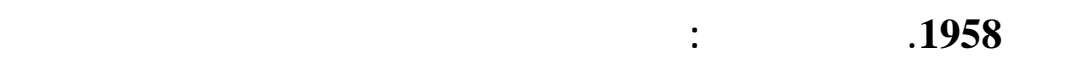

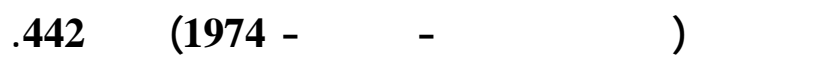

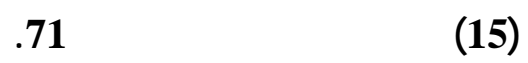

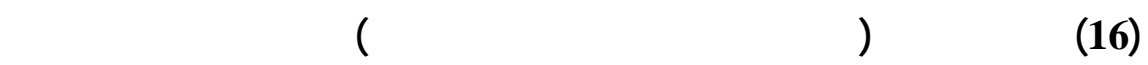

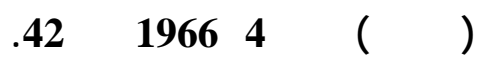


(17) Shahram Cubin and Sepehr ZabIh, The Foreign Relation of Iran, (London-1974), P.158.

$$
\text { روضافي، المصر للسلق، ص419. }
$$

(19) Nadaf Safran، Saudi Arabia، (London-1984)، P.119.

$$
\text { (20) باليب، المصدر الساق، ص ص } 74 \text {-75. }
$$

(21) Fred Halliday, Arabia with Out Sultans، (London-1974), P.113.

$$
\begin{aligned}
& \text { (22) باليب، المصر اللسلق، ص ص74 -75. } \\
& \text { (23) الزباني، المصر السلب، صب132. } \\
& \text { (24) باليب، المصدر السلق، صل70. }
\end{aligned}
$$

(25) رالشد البرالوي، من حلف حلف بهداد الل الحلف السلاي، (مكتب مة النهض مة

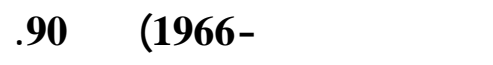

(26) Ramesh Sanghri, The Shah of Iran Apolitical Biography. (London-1968), P.319.

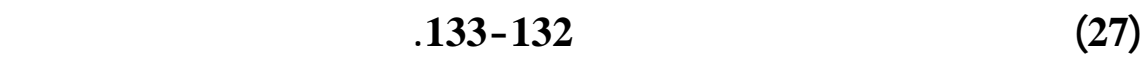

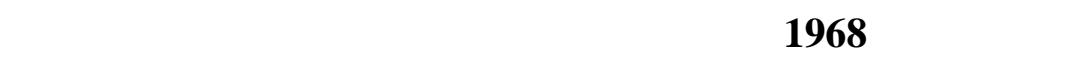

تحسيد المتداد الجرف الفاري بين البلبن في المطاقة المغمورة بينهما وتعي ين

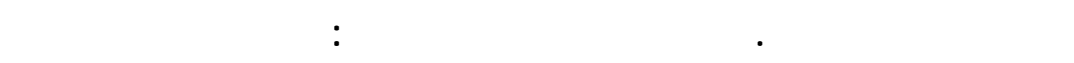

$$
\begin{aligned}
& \text { فوق الرهل، (الاهلية اللبنلنية - بيروت - 1966)، ص 215. } \\
& \text { (28) باليب، المصدر السالق، صول } 77 .
\end{aligned}
$$

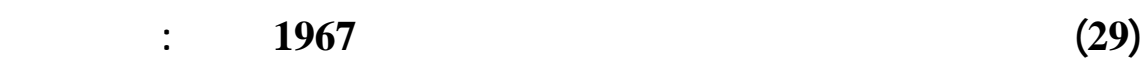

$$
\text { المصر السلق، ص ص53 -60. }
$$

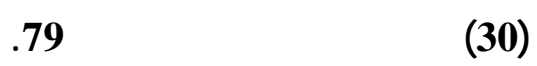

(31) محمد رضافوه، الملفلت الايرلنية - الخليجية، (مركز الدرلس الت العردمي

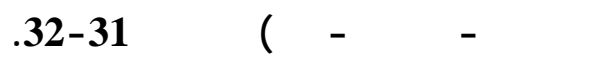


(32) قلم، المصرالسلق، ص ص142-143.

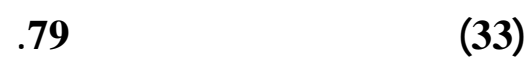

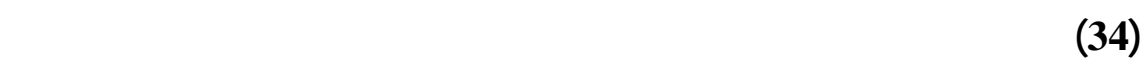

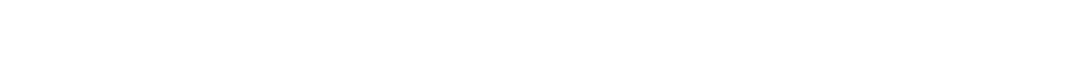

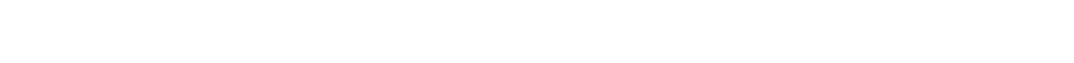

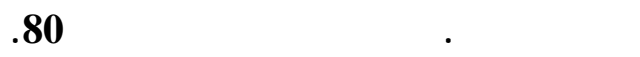

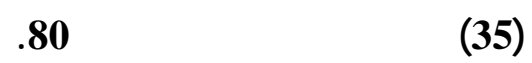

(36) نذير فنصة، عامفة عل اللشرق الاوطم، (دار الفاق الجيسة - بيروت -

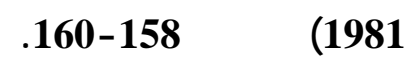

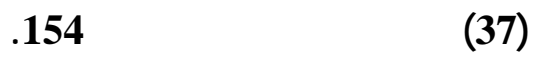

(38) محمد علب جنلب، خلبج فاوس الشنائي بالمارلت لن، (جلبشريعت وشرق طهرلن -1329)، صائ1372.

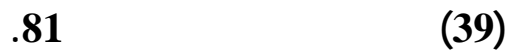

(40) Abir, Op.cit, p.18

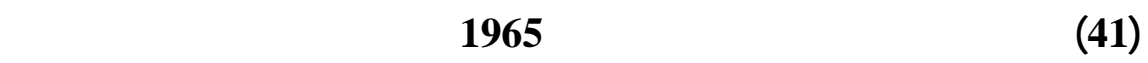

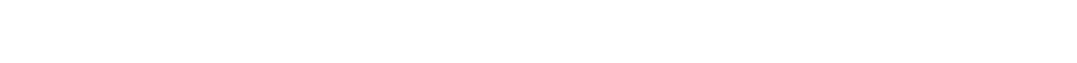

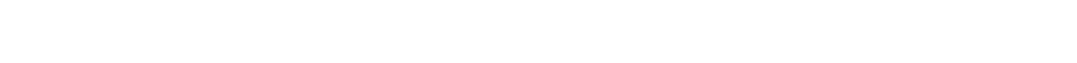

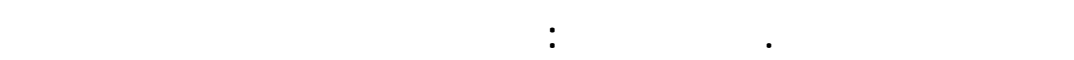

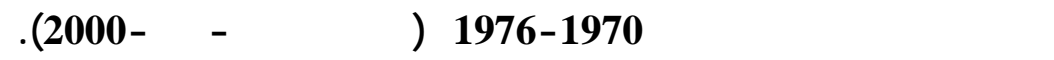
(42) قلم، المصدر السلق، صص المص 148 -149.

(43) Rouhollah K. Ramazani, (Iran Search for Regional Cooperation), The Middle East Journal, (USA) Vol. 30, No. l, 1976.p.166. 


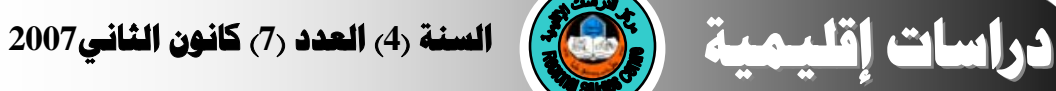

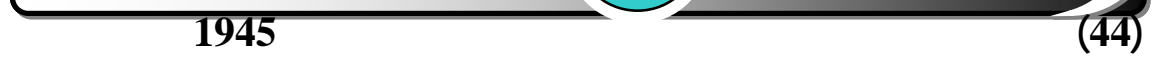

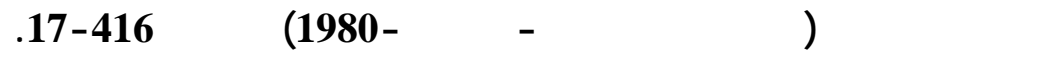

Safran, OP. cit, P. 177.

(45)طرح الرئس المريكي نيكسون طشروعاً تضمن قليص الالتزاملت والفقلت

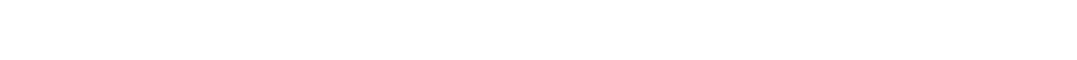

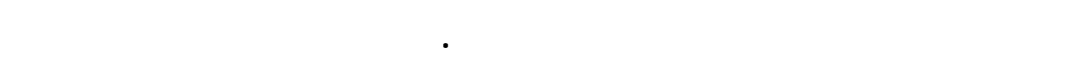

الايرانية ازاء الخلبج الهرم حق الثمانينلت، (مركز درلسلت الخلبج العري -

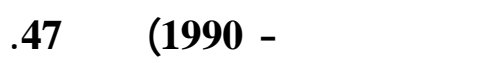

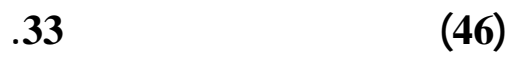

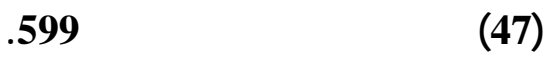

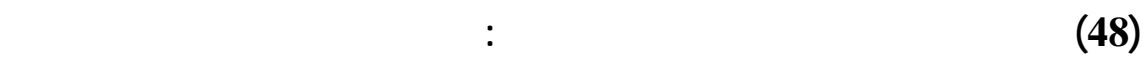

الامنية في الخلبج العري، رؤبة عربية، (مركز درلسلت الخلبج العري -

$$
\text { جامعة البصرة -1983). }
$$

(49) Ramazani, OP. cit, P. 166.

(50)(سلامة، المصر للسلق، ص 608. 


\title{
Iranian- Saudi Relations 1941 - 1979 \\ "A historical Political Study"
}

\author{
By : Dr. Mohammed A . Younis Edan
}

\begin{abstract}
The paper spots light on studying the relations between Iran and Saudi Arabia between 1941 -1979 and the most important regional and international developments which had left its impacts upon such relations.

These relation were characterized by stability and improvement all over the period of the study. It can be described since 1927 till 1953 as a stage of fixing and establishing these relations, as well as looking for means and methods of developing them As for the relations during the period 1953- 1964, we can say that it had witnessed longstanding ways while the period between 1964 -1979, it was a flourishing period. Due to the huge compatibility between both states in the political, economic and security aspects which had been reflected upon the politics of both state, we can could see its roots clearly.
\end{abstract}

